\title{
Therapeutic suppression of proteolipid protein rescues Pelizaeus- Merzbacher Disease in mice
}

Matthew S. Elitt ${ }^{1}$, Lilianne Barbar ${ }^{1}$, H. Elizabeth Shick ${ }^{1}$, Berit E. Powers ${ }^{2}$, Yuka MaenoHikichi $^{1}$, Mayur Madhavan ${ }^{1}$, Kevin C. Allan ${ }^{1}$, Baraa S. Nawash ${ }^{1}$, Zachary S. Nevin ${ }^{1}$, Hannah E. Olsen $^{1}$, Midori Hitomi ${ }^{3}$, David F. LePage ${ }^{1}$, Weihong Jiang ${ }^{1}$, Ronald A. Conlon ${ }^{1}$, Frank Rigo ${ }^{2}$, Paul J. Tesar ${ }^{1 *}$

${ }^{1}$ Department of Genetics and Genome Sciences, Case Western Reserve University School of Medicine, Cleveland, Ohio 44106, USA.

${ }^{2}$ Ionis Pharmaceuticals, Carlsbad, California 92008, USA.

${ }^{3}$ Lerner Research Institute, Cleveland Clinic Foundation, Cleveland, Ohio 44106, USA.

*email: paul.tesar@case.edu

Mutations in proteolipid protein 1 (PLP1) result in failure of myelination and severe neurological dysfunction in the $X$-linked pediatric leukodystrophy Pelizaeus-Merzbacher disease (PMD). The majority of PLP1 variants, including supernumerary copies and various point mutations, lead to early mortality. However, PLP1-null patients and mice display comparatively mild phenotypes, suggesting that reduction of aberrant PLP1 expression might provide a therapeutic strategy across PMD genotypes. Here we show, CRISPR-Cas9 mediated germline knockdown of Plp1 in the severe jimpy ( $P$ lp $1^{\mathrm{jp}}$ ) point mutation mouse model of PMD rescued myelinating oligodendrocytes, nerve conduction velocity, motor function, and lifespan to wild-type levels, thereby validating PLP1 suppression as a therapeutic approach. To evaluate the therapeutic potential of Plp1 suppression in postnatal PMD mice, we tested antisense oligonucleotides (ASOs) that stably decrease mouse Plp1 mRNA and protein in vivo. Administration of a single intraventricular dose of Plpl-targeted ASOs to postnatal jimpy mice increased myelination, improved motor behavior, and extended lifespan through an 8-month endpoint. Collectively, these results support the development of PLPI suppression as a disease-modifying therapy for most PMD patients. More broadly, we demonstrate that RNA therapeutics can be delivered to oligodendrocytes in vivo to modulate neurological function and lifespan, opening a new treatment modality for myelin disorders. 


\section{Main text:}

Pelizaeus-Merzbacher disease (PMD; OMIM 312080) is an X-linked leukodystrophy typified by extensive hypomyelination of the central nervous system (CNS). Symptoms typically present early in childhood with a constellation of nystagmus, spasticity, hypotonia, and cognitive dysfunction, leading to mortality in early adulthood. In severe forms, symptoms present connatally and patients succumb to their disease in early childhood. Despite intense interest in PMD therapeutic development, including several clinical trials, no disease modifying therapies have proven efficacious in patients ${ }^{1-6}$.

Mutations in the proteolipid protein 1 (PLP1; OMIM 300401) gene underlie the pathogenesis of PMD, with variability in disease onset and progression dictated by the severity of the particular mutation ${ }^{7-9}$. PLP1 codes for the tetraspan protein PLP as well as its shorter splice isoform DM20, which lacks 35 amino acids in the cytosolic loop region ${ }^{10}$. PLP/DM20 is highly conserved across species, with human, mouse, and rat sharing identical amino acid sequence ${ }^{11}$. Expression of $P L P 1$ is largely restricted to myelinating oligodendrocytes, where it is responsible for $\sim 50 \%$ of the total protein content of myelin ${ }^{12}$.

The majority of PMD cases result from duplications in $P L P 1$ yielding overexpression of otherwise normal PLP protein ${ }^{8}$. Additionally, hundreds of unique point mutations in PLPl which each generate abnormal PLP protein have also been discovered in patients with severe disease. Interestingly, while $P L P 1$ deletions are uncommon, null patients and mice display symptoms that are significantly delayed and more mild compared to those with duplications or point mutations ${ }^{13-}$ ${ }^{15}$. Null patients can live until 40-60 years old ${ }^{8,16}$, do not develop lower body spastic paraparesis until the second or third decade of life, and do not demonstrate cognitive regression until the third or fourth decade of life (see Extended Data Table 1 for detailed clinical presentations of PLP1null patients from published reports). 
Collectively, this clinical landscape provides several potential opportunities for therapeutic development. While never tested, knockout or suppression of the duplicated copy of PLP1 should, in theory, correct elevated protein expression to normal levels in patients harboring duplications. More globally, we suggest that the mild presentation of null patients provides rationale for a

case. Such an approach would provide comprehensive therapy to include the litany of point mutations that generate abnormal PLP protein, abrogating the need for personalized therapy tailored to each patient's severe, individual mutation.

To test this latter strategy, we evaluated Plpl suppression as a therapeutic approach for PMD using the jimpy $\left(P l p 1^{j p}\right)$ mouse, which expresses a mutant PLP protein due to a point mutation in splice acceptor site of intron 4 of $P l p 1$, leading to exon 5 skipping and a frameshift affecting the final 70 amino acids in the C-terminus of PLP/DM20. Jimpy mice exhibit severe neurological symptoms, die at 3 weeks of age, and accurately reflect the cellular and molecular pathology seen in human disease. To test if $P l p l$ suppression was a valid therapeutic strategy for PMD we first utilized nuclease-mediated cleavage of DNA by clustered regularly interspaced short palindromic repeat-associated 9 (CRISPR-Cas9) protein ${ }^{17,18}$ with synthetic guide RNAs (sgRNA) targeted to induce a frameshift in PLP1 exon 3 and trigger subsequent knockdown of Plpl mRNA by nonsense-mediated decay. Plpl-targeting sgRNAs were designed and tested for on-target cutting efficiency and two sgRNAs (3 and 7) were administered to knockdown Plpl by germline editing of jimpy mice (Fig. 1a). Concomitant administration of both sgRNAs with Cas9 mRNA from Streptococcus pyogenes (spCas9) in zygotes from crosses of jimpy-carrier females with wildtype males generated mice with high on-target mutation efficiency in Plpl (Extended Data Fig. 1a). These founders included a jimpy male with complex deletion of 80 total nucleotides of DNA 
in exon 3 of his single copy of Plpl on the X chromosome, resulting in a frameshift in exon 3 and an early termination codon in exon 4 (Fig. 1a and Extended Data Fig. 1b). This mouse denoted

.

$$
\text { "CR-impy" (for CRISPR frameshift-mediated knockdown of Plpl in jimpy) showed no overt }
$$

neurological phenotypes. A line of CR-impy was bred to evaluate cellular, molecular, and functional phenotypes, along with contemporaneous, isogenic wild-type and jimpy male mice.

As expected jimpy males displayed the typical pathological phenotypes including severe tremor, ataxia, seizures (lasting >30 seconds), and death by the third postnatal week (Fig. 1b, Supplementary Fig. 1, Supplementary Video 1). In contrast, CR-impy mice, which had a 61-74\% reduction Plpl transcript expression in multiple brain regions (Extended Data Fig. 1c), showed a 21-fold increase in lifespan (mean survival = 23 and 489 days in jimpy and CR-impy, respectively) with no overt tremor, ataxia, or evidence of seizures through the terminal endpoint at 18 months of age (Fig. 1b, Supplementary Fig. 1, Supplementary Video 1, and Supplementary Video 2).

Assessment of CR-impy mice at 3 weeks, 6 months, and 18 months of age by immunohistochemistry revealed a stable restoration of oligodendrocytes to near wild-type levels throughout the neuraxis, as evidenced by expression of the mature myelin marker myelin basic protein (MBP), and quantification of oligodendrocyte number using the oligodendrocyte-specific transcription factor myelin regulatory factor (MyRF) (Fig. 1c-e). Quantification of MBP protein by western blot and RNA by qRT-PCR further supported these findings, revealing 40-95\% restoration of MBP at 3 weeks and full restoration of $M b p$ expression and MBP at 6 months of age across multiple brain regions in CR-impy mice compared to wild-type (Extended Data Fig. 1d-f). Restoration of oligodendrocytes in CR-impy mice grossly reduced reactivity of microglia and astrocytes normally seen in jimpy mice at 3 weeks of age, and was sustained into adulthood (Extended Data Fig. 2a, b). Finally, MBP+ CR-impy oligodendrocytes ensheathed phospho- 
neurofilament+ axons in a similar manner to wild-type samples (Fig. 1f), suggestive of a potentially comparable myelination status.

Electron micrographs and tissue sections stained with toluidine blue demonstrated increased myelination in CR-impy mice. Examination of optic nerves, which provide straightforward quantification of myelination from aligned axons, revealed a significant 6-fold improvement in the number and density of myelinated axons in CR-impy animals, reaching 53\% of wild-type levels at 3 weeks of age (Fig. 1g, h, and Extended Data Fig. 3a). Myelination in CRimpy animals was sustained through 6 month and 18 month time points, approaching wild-type levels (Fig. 1i and Extended Data Fig. 3b, c). Additionally, examination of corpus callosum myelin at 3 weeks (Extended Data Fig. 3d) further revealed that these improvements were not restricted to the optic nerve but manifested throughout the neuraxis of CR-impy mice.

Although the quantity of myelin increased drastically compared to jimpy, we noted that CR-impy myelin sheaths were not quite as compact as those seen in age-matched wild type controls. To determine if restored myelin in CR-impy mice was functional we used electrophysiology to measure conduction velocity in the optic nerve at two time points. At 3 weeks of age we found a significant 2.6- and 1.7-fold increase in $1^{\text {st }}$ and $2^{\text {nd }}$ peak conduction velocities, respectively, in CR-impy mice compared to jimpy. Intriguingly, these values trailed wild-type conduction velocities, a finding consistent with our quantitative electron microscopy showing an incomplete restoration of myelinated axons at the 3 week time point. However, over time this discrepancy disappeared and by 6 months of age we found no significant difference in optic nerve conduction velocity in CR-impy mice relative to wild-type (Fig. 2a, b), suggesting that suppression of Plpl does not impair myelin function. 
Finally, we wanted to determine if the widespread restoration of CR-impy oligodendrocytes resulted in a meaningful recovery of motor performance using the accelerating rotarod and open field behavioral assays at 3 weeks, 2 months, 6 months, and 18 months of age. In rotarod testing, which measures motor learning, function, and coordination, CR-impy mice showed equivalent performance to wild-type up through 6 months of age. At the final 18 month time point we noted a slight decrease in CR-impy performance relative to wild-type (Fig. 2c). This is consistent with prior reports in mice with complete $P l p l$ knockout in otherwise wild-type mice, which showed a decline in rotarod performance in late adulthood relative to wild-type due to long tract axon degeneration ${ }^{13}$. Overall locomotion of CR-impy mice in open field testing was equivalent to wildtype at all time points tested (Fig. 2d). Together, these results establish that frameshift-mediated knockdown of mutant Plpl in PMD mice prevents disease with near complete restoration of oligodendrocytes, functional myelin, and lifespan.

PMD is thought to result from a cell-intrinsic deficit within the oligodendrocyte lineage ${ }^{19-}$ 23. In the CNS, PLP (protein) is restricted to oligodendrocytes, but Plpl transcript and transgene expression have been reported in a few neuronal subsets ${ }^{24}$. Since CR-impy mice have constitutive germline Plpl knockdown in all cells, we generated and validated induced pluripotent stem cells (iPSCs) from isogenic wild-type, CR-impy, and jimpy mice (Extended Data Fig. 4a, b) to generate pure populations of oligodendrocyte progenitor cells (OPCs) and assess the cell type specific effect of Plpl knockdown, in vitro ${ }^{25,26}$. OPCs expressing the canonical transcription factors Olig2 and Sox10 (Extended Data Fig. 4c, d) were stimulated to differentiate towards an oligodendrocyte fate by addition of thyroid hormone, and MBP+ oligodendrocytes were quantified. As expected ${ }^{22}$, jimpy cultures contained only rare surviving $\mathrm{MBP}+$ oligodendrocytes with a concomitant loss in total cells (Fig. 3a-c). In contrast CR-impy cultures showed a complete rescue of $\mathrm{MBP}+$ 
oligodendrocytes as well as total cells (Fig. 3a-c). These results suggest that oligodendrocyte restoration in CR-impy mice is due to an amelioration of intrinsic cellular pathology within the oligodendrocyte lineage.

After genetically validating Plpl knockdown as a therapeutic target for diseasemodification in PMD, we pursued a clinically translatable strategy for in vivo, postnatal suppression of Plp1. While postnatal delivery of CRISPR-based therapeutics has demonstrated pre-clinical efficacy in a separate CNS disorder ${ }^{27}$, delivery challenges, off-target risks ${ }^{28,29}$, and employ anti-sense oligonucleotides (ASOs) to test suppression of Plpl. ASOs are short singlestranded oligodeoxynucleotides with chemical modifications that confer enhanced pharmacological properties including robust in vivo stability, target affinity, and cellular uptake when delivered directly to the CNS since they do not cross the blood-brain barrier ${ }^{32,33}$. ASOs bind to their target RNAs through complementary base pairing and can be designed to modify RNA splicing or form an ASO/RNA hybrid that is recognized by RNase H1, leading to cleavage of the target transcript and concomitant reduction in protein expression. Recently, ASOs have shown remarkable efficacy in several animal models of neuron-based CNS disorders and human spinal muscular atrophy patients, the latter leading to the first FDA-approved therapy for this disease ${ }^{34-}$ 44. Whether ASOs could be delivered to oligodendrocytes in vivo and mediate functional improvement in the context of myelin disease was unknown.

We tested two separate RNase H ASOs targeting the $5^{\text {th }}$ intron (ASO Plpl.a) and 3'UTR (ASO Plpl.b) of Plpl (Fig. 4a). Administration of ASO Plpl.a or ASO Plpl.b by intracerebroventricular (ICV) injection robustly reduced $P l p l$ expression by $93 \%$ and $86 \%$ in the cortex and $97 \%$ and $94 \%$ in the spinal cord of adult wild-type mice, respectively (Extended Data 
Fig. 5a). Both of these Plpl-targeting ASOs were well-tolerated based on CNS histology and lack of alteration or reactivity of glial and immune cell markers by qRT-PCR and immunohistochemistry 8 weeks after dosing adult wild-type mice (Extended Data Fig. 5b-f).

Administration of ASO Plp1.a, ASO Plp1.b, or a non-targeting control ASO by ICV injection to male pups after birth revealed widespread distribution and stability of ASOs throughout the neuraxis in both wild-type and jimpy mice based on whole-brain immunohistochemical staining at 3 weeks (Fig. 4a, b, and Extended Data Fig. 6a, b). In wild-type mice, Plp1-targeting ASOs delivered with this single dose treatment regimen showed robust reductions in Plpl transcript by 46-90\% and PLP protein by 47-63\% across multiple CNS regions, but importantly had no effect on MBP protein levels or overt phenotype (Extended Data Fig. 7a-c and Supplementary Fig. 3). As expected, jimpy mice treated with non-targeting control ASO and those left untreated succumbed to their disease at the third postnatal week (Fig. 4c). However, jimpy mice treated after birth with a single ICV dose of Plp1-targeting ASOs (Plpl.a or Plp1.b) induced a remarkable extension of lifespan, to our terminal endpoint of 8 months of age (when all animals were processed for histology) (Fig. 4b, c, Supplementary Fig. 3, Supplementary Video 3, and Supplementary Video 4).

Treatment with Plp1-targeting ASOs increased oligodendrocytes in jimpy animals by 3 weeks of age, notably in the brainstem, which was sustained through the 8 month terminal end point without additional ASO dosing or other intervention (Fig. 4d-f and Extended Data Fig. 7d, e). Electron micrographs and tissue sections stained with toluidine blue confirmed that some myelinated axons were still present even 8 months post-treatment, but overall myelination was reduced relative to wild-type controls (Fig. 4g, h). Symptomatically, Plpl-targeting ASO-treated jimpy mice showed only minor PMD pathological phenotypes, including slight tremor and 
occasional short duration seizures ( $<15$ seconds), but otherwise appeared overtly normal in daily activities including the ability to breed, which has not previously been achieved by a jimpy male mouse (Supplementary Fig. 3). Rotarod performance of Plpl-targeting ASO-treated jimpy mice lagged below wild-type levels, but, strikingly, overall locomotion was restored to wild-type levels across 2 month, 4 month, and 6 month time points (Fig. 4i, j). Together these data demonstrate that a single postnatal administration of ASOs elicits a sustained reduction in Plpl expression and dramatically improves myelination, motor performance, and lifespan in a severe point mutation model of PMD.

In summary, we have shown CRISPR- and ASO-mediated rescue of PMD in the severely affected jimpy mouse model through two independent, technological modalities to achieve mutant Plpl suppression. We demonstrate that RNA-based drugs can be used to modulate a disease target in oligodendrocytes to restore both functional myelin and lifespan in the context of a severe genetic disorder. These results provide powerful foundational data for the development of clinically relevant ASO technology to achieve postnatal reduction of Plp1. While further pre-clinical development is needed to optimize the dosing regimen, our results highlight that even a single ASO treatment can elicit a profound and sustained phenotypic improvement.

The genetic spectrum of PMD patients encompasses hundreds of unique mutations. Our data nominates a mutation-agnostic approach to collapse this heterogeneity through suppression of $P L P 1$, potentially abrogating the need for per-patient, personalized therapies. Importantly, while mice display minimal phenotype when Plpl is knocked out ${ }^{13,14,45}, P L P l$-null patients present with neurological disease, but with considerably later onset, slower progression, and improved clinical outcomes. While careful titration of normal PLPI expression to wild-type levels could be curative for the majority of patients who harbor gene duplications, reducing mutant PLP1 in patients with 
point mutations, while not a full cure, may provide substantial improvement for this disease, which

currently has no viable treatment options. Collectively our studies, combined with the feasibility

of ASO delivery to the human CNS and current safety data in other CNS indications, support

advancement of $P L P 1$ suppression into the clinic as a disease modifying therapeutic with potential

universal applicability to PMD patients. More broadly, our data provide a framework to modulate

pathogenic genes or mRNAs in OPCs and oligodendrocytes in order to restore myelination and

neurological function in additional genetic and sporadic disorders of myelin.

\section{References:}

1 Goldman, S. A., Nedergaard, M. \& Windrem, M. S. Glial progenitor cell-based treatment and modeling of neurological disease. Science 338, 491-495, doi:10.1126/science.1218071 (2012).

2 Gupta, N. et al. Neural stem cell engraftment and myelination in the human brain. Sci Transl Med 4, 155ra137, doi:10.1126/scitranslmed.3004373 (2012).

3 Saher, G. et al. Therapy of Pelizaeus-Merzbacher disease in mice by feeding a cholesterol-enriched diet. Nat Med 18, 1130-1135, doi:10.1038/nm.2833 (2012).

4 Prukop, T. et al. Progesterone antagonist therapy in a Pelizaeus-Merzbacher mouse model. Am J Hum Genet 94, 533-546, doi:10.1016/j.ajhg.2014.03.001 (2014).

5 Wishnew, J. et al. Umbilical cord blood transplantation to treat Pelizaeus-Merzbacher Disease in 2 young boys. Pediatrics 134, e1451-1457, doi:10.1542/peds.2013-3604 (2014).

6 Tantzer, S., Sperle, K., Kenaley, K., Taube, J. \& Hobson, G. M. Morpholino Antisense Oligomers as a Potential Therapeutic Option for the Correction of Alternative Splicing in PMD, SPG2, and HEMS. Mol Ther Nucleic Acids 12, 420-432, doi:10.1016/j.omtn.2018.05.019 (2018).

7 Cailloux, F. et al. Genotype-phenotype correlation in inherited brain myelination defects due to proteolipid protein gene mutations. Clinical European Network on Brain Dysmyelinating Disease. Eur J Hum Genet 8, 837-845, doi:10.1038/sj.ejhg.5200537 (2000).

8 Inoue, K. PLP1-related inherited dysmyelinating disorders: Pelizaeus-Merzbacher disease and spastic paraplegia type 2. Neurogenetics 6, 1-16, doi:10.1007/s10048-004-0207-y (2005).

9 Hobson, G. M. \& Garbern, J. Y. Pelizaeus-Merzbacher disease, Pelizaeus-Merzbacherlike disease 1, and related hypomyelinating disorders. Semin Neurol 32, 62-67, doi:10.1055/s-0032-1306388 (2012).

10 Nave, K. A., Lai, C., Bloom, F. E. \& Milner, R. J. Splice site selection in the proteolipid protein (PLP) gene transcript and primary structure of the DM-20 protein of central nervous system myelin. Proceedings of the National Academy of Sciences of the United States of America 84, 5665-5669 (1987). 
11 Garbern, J. Y. Pelizaeus-Merzbacher disease: Genetic and cellular pathogenesis. Cell Mol Life Sci 64, 50-65, doi:10.1007/s00018-006-6182-8 (2007).

12 Baumann, N. \& Pham-Dinh, D. Biology of oligodendrocyte and myelin in the mammalian central nervous system. Physiol Rev 81, 871-927 (2001).

13 Griffiths, I. et al. Axonal swellings and degeneration in mice lacking the major proteolipid of myelin. Science 280, 1610-1613 (1998).

14 Klugmann, M. et al. Assembly of CNS myelin in the absence of proteolipid protein. Neuron 18, 59-70 (1997).

15 Garbern, J. Y. et al. Patients lacking the major CNS myelin protein, proteolipid protein 1, develop length-dependent axonal degeneration in the absence of demyelination and inflammation. Brain 125, 551-561 (2002).

16 Hobson, G. M. \& Kamholz, J. in GeneReviews $((R))$ (eds M. P. Adam et al.) (1993).

17 Jinek, M. et al. A programmable dual-RNA-guided DNA endonuclease in adaptive bacterial immunity. Science 337, 816-821, doi:10.1126/science.1225829 (2012).

18 Cong, L. et al. Multiplex genome engineering using CRISPR/Cas systems. Science 339, 819-823, doi:10.1126/science.1231143 (2013).

19 Dhaunchak, A. S. \& Nave, K. A. A common mechanism of PLP/DM20 misfolding causes cysteine-mediated endoplasmic reticulum retention in oligodendrocytes and Pelizaeus-Merzbacher disease. Proceedings of the National Academy of Sciences of the United States of America 104, 17813-17818, doi:10.1073/pnas.0704975104 (2007).

20 Gow, A., Southwood, C. M. \& Lazzarini, R. A. Disrupted proteolipid protein trafficking results in oligodendrocyte apoptosis in an animal model of Pelizaeus-Merzbacher disease. J Cell Biol 140, 925-934 (1998).

21 Nevin, Z. S. et al. Modeling the Mutational and Phenotypic Landscapes of PelizaeusMerzbacher Disease with Human iPSC-Derived Oligodendrocytes. Am J Hum Genet 100, 617-634, doi:10.1016/j.ajhg.2017.03.005 (2017).

22 Elitt, M. S. et al. Chemical Screening Identifies Enhancers of Mutant Oligodendrocyte Survival and Unmasks a Distinct Pathological Phase in Pelizaeus-Merzbacher Disease. Stem Cell Reports 11, 711-726, doi:10.1016/j.stemcr.2018.07.015 (2018).

23 Luders, K. A., Patzig, J., Simons, M., Nave, K. A. \& Werner, H. B. Genetic dissection of oligodendroglial and neuronal Plp1 function in a novel mouse model of spastic paraplegia type 2. Glia 65, 1762-1776, doi:10.1002/glia.23193 (2017).

24 Miller, M. J., Kangas, C. D. \& Macklin, W. B. Neuronal expression of the proteolipid protein gene in the medulla of the mouse. J Neurosci Res 87, 2842-2853, doi:10.1002/jnr.22121 (2009).

25 Lager, A. M. et al. Rapid functional genetics of the oligodendrocyte lineage using pluripotent stem cells. Nat Commun 9, 3708, doi:10.1038/s41467-018-06102-7 (2018).

26 Najm, F. J. et al. Rapid and robust generation of functional oligodendrocyte progenitor cells from epiblast stem cells. Nature methods 8, 957-962, doi:10.1038/nmeth.1712 (2011).

27 Lee, B. et al. Nanoparticle delivery of CRISPR into the brain rescues a mouse model of fragile X syndrome from exaggerated repetitive behaviours. Nature Biomedical Engineering, doi:10.1038/s41551-018-0252-8 (2018).

28 Anderson, K. R. et al. CRISPR off-target analysis in genetically engineered rats and mice. Nature methods 15, 512-514, doi:10.1038/s41592-018-0011-5 (2018). 
29 Tsai, S. Q. \& Joung, J. K. Defining and improving the genome-wide specificities of CRISPR-Cas9 nucleases. Nature reviews. Genetics 17, 300-312, doi:10.1038/nrg.2016.28 (2016).

30 Kosicki, M., Tomberg, K. \& Bradley, A. Repair of double-strand breaks induced by CRISPR-Cas9 leads to large deletions and complex rearrangements. Nature biotechnology 36, 765-771, doi:10.1038/nbt.4192 (2018).

31 van Overbeek, M. et al. DNA Repair Profiling Reveals Nonrandom Outcomes at Cas9Mediated Breaks. Molecular cell 63, 633-646, doi:10.1016/j.molcel.2016.06.037 (2016).

32 Rinaldi, C. \& Wood, M. J. A. Antisense oligonucleotides: the next frontier for treatment of neurological disorders. Nat Rev Neurol 14, 9-21, doi:10.1038/nrneurol.2017.148 (2018).

33 Bennett, C. F., Baker, B. F., Pham, N., Swayze, E. \& Geary, R. S. Pharmacology of Antisense Drugs. Annu Rev Pharmacol Toxicol 57, 81-105, doi:10.1146/annurevpharmtox-010716-104846 (2017).

34 Finkel, R. S. et al. Treatment of infantile-onset spinal muscular atrophy with nusinersen: a phase 2, open-label, dose-escalation study. Lancet 388, 3017-3026, doi:10.1016/S01406736(16)31408-8 (2016).

35 Hagemann, T. L. et al. Antisense suppression of glial fibrillary acidic protein as a treatment for Alexander disease. Ann Neurol 83, 27-39, doi:10.1002/ana.25118 (2018).

36 Finkel, R. S. et al. Nusinersen versus Sham Control in Infantile-Onset Spinal Muscular Atrophy. N Engl J Med 377, 1723-1732, doi:10.1056/NEJMoa1702752 (2017).

37 Kordasiewicz, H. B. et al. Sustained therapeutic reversal of Huntington's disease by transient repression of huntingtin synthesis. Neuron 74, 1031-1044, doi:10.1016/j.neuron.2012.05.009 (2012).

38 Crooke, S. T., Witztum, J. L., Bennett, C. F. \& Baker, B. F. RNA-Targeted Therapeutics. Cell Metab 27, 714-739, doi:10.1016/j.cmet.2018.03.004 (2018).

39 DeVos, S. L. et al. Tau reduction prevents neuronal loss and reverses pathological tau deposition and seeding in mice with tauopathy. Sci Transl Med $\mathbf{9}$, doi:10.1126/scitranslmed.aag0481 (2017).

40 Miller, T. M. et al. An antisense oligonucleotide against SOD1 delivered intrathecally for patients with SOD1 familial amyotrophic lateral sclerosis: a phase 1, randomised, first-inman study. Lancet Neurol 12, 435-442, doi:10.1016/S1474-4422(13)70061-9 (2013).

41 Becker, L. A. et al. Therapeutic reduction of ataxin-2 extends lifespan and reduces pathology in TDP-43 mice. Nature 544, 367-371, doi:10.1038/nature22038 (2017).

42 Meng, L. et al. Towards a therapy for Angelman syndrome by targeting a long noncoding RNA. Nature 518, 409-412, doi:10.1038/nature13975 (2015).

43 Passini, M. A. et al. Antisense oligonucleotides delivered to the mouse CNS ameliorate symptoms of severe spinal muscular atrophy. Sci Transl Med 3, 72ra18, doi:10.1126/scitranslmed.3001777 (2011).

44 Scoles, D. R. et al. Antisense oligonucleotide therapy for spinocerebellar ataxia type 2. Nature 544, 362-366, doi:10.1038/nature22044 (2017).

45 Gould, E. A. et al. Mild myelin disruption elicits early alteration in behavior and proliferation in the subventricular zone. eLife 7, doi:10.7554/eLife.34783 (2018).

46 Hsu, P. D. et al. DNA targeting specificity of RNA-guided Cas9 nucleases. Nature biotechnology 31, 827-832, doi:10.1038/nbt.2647 (2013). 
47 Nakagata, N., Okamoto, M., Ueda, O. \& Suzuki, H. Positive effect of partial zonapellucida dissection on the in vitro fertilizing capacity of cryopreserved C57BL/6J transgenic mouse spermatozoa of low motility. Biol Reprod 57, 1050-1055 (1997).

48 Schmid-Burgk, J. L. et al. OutKnocker: a web tool for rapid and simple genotyping of designer nuclease edited cell lines. Genome Res 24, 1719-1723, doi:10.1101/gr.176701.114 (2014).

49 Glascock, J. J. et al. Delivery of therapeutic agents through intracerebroventricular (ICV) and intravenous (IV) injection in mice. J Vis Exp, doi:10.3791/2968 (2011).

Acknowledgments This research was supported, in part, by grants from the NIH R01NS093357 (P.J.T.), T32GM007250 (M.S.E, Z.S.N., K.C.A), and F30HD084167 (Z.S.N.); the New York Stem Cell Foundation (P.J.T); the European Leukodystrophy Association (P.J.T.); and philanthropic contributions from the Geller, Goodman, Fakhouri, Long, Peterson, and Weidenthal families. Additional support was provided by the Genomics, Small Molecule Drug Development, and Rodent Behavioral core facilities of the Case Western Reserve University (CWRU) Comprehensive Cancer Center (P30CA043703), the CWRU Light Microscopy Imaging Center (S10-OD016164), and the electron microscopy division of the Cleveland Clinic Lerner Research Institute Imaging Core. We are grateful to Lynn Landmesser, Robert Miller, Peter Scacheri, Tony Wynshaw-Boris, Ben Clayton, Simone Edelheit, Alex Miron, Hiroyuki Arakawa, Lucille Hu, Chris Allan, and Jared Cregg for technical assistance and discussion.

Author contributions M.S.E. and P.J.T. conceived and managed the overall study. H.E.S and M.S.E. maintained the animal colonies, tracked survival, and harvested animal tissues. M.S.E. captured video recordings. L.B. and M.S.E. designed and tested sgRNAs. D.F.L., R.A.C., and W.J. performed zygote electroporation and oviduct transfers. H.E.S., B.S.N., K.C.A., and L.B. performed western blotting and protein quantitation. B.E.P, L.B., and K.C.A. performed qRTPCR. M.M., B.S.N, L.B., H.E.S., and M.S.E. generated the immunohistochemistry data. Y.M. performed optic nerve electrophysiology studies. Y.M., M.H., and H.E.S. processed samples for histology and electron microscopy and analyzed images. M.S.E, K.C.A., B.S.N., and L.B. performed animal behavior. M.S.E., B.S.N., and H.E.O. generated and characterized iPSCs and OPCs in vitro. B.E.P. and F.R. designed and characterized ASOs, tested tolerability in adult mice, recommended the use of ASOs, and contributed to the study design and interpretation of results in the ASO-treated disease model. M.S.E. performed ASO injections in pups. Z.S.N. contributed key components to experimental design, data analysis, and manuscript composition. M.S.E., M.M., L.B., and P.J.T. assembled figures. M.S.E. and P.J.T. wrote the manuscript with input from all authors.

Competing interests P.J.T. is a co-founder and consultant for Convelo Therapeutics, which has licensed patents from CWRU inventors (P.J.T., M.S.E., Z.S.N., and M.M.). P.J.T. and CWRU retain equity in Convelo Therapeutics. P.J.T. is a consultant and on the Scientific Advisory Board of Cell Line Genetics, which performed karyotyping in this study. P.J.T. is Chair of the Scientific Advisory Board (volunteer position) for the Pelizaeus-Merzbacher Disease Foundation. B.E.P. and F.R. are employees of Ionis Pharmaceuticals. No other authors declare competing interests.

Data availability All data generated or analyzed during this study are included in this article and its supplementary information files. Source data for animal survival cohorts in Figs. 1b, 2c, d, and 4c, i, j and are provided in Supplementary Figs. 1 and 3. Raw annotated western blot images for Extended Data Fig. 1d, f and Extended Data Fig. 7b, c, e are provided as Supplementary Figs. 2 and 4. Animals and iPSC lines are available from P.J.T. upon request. 
Materials and Methods:

Mice. All procedures were in accordance with the National Institutes of Health Guidelines for the

Care and Use of Laboratory Animals and were approved by the Case Western Reserve University Institutional Animal Care and Use Committee (IACUC).

Wildtype (B6CBACa-Aw-J/A) and jimpy (B6CBACa-Aw-J/A-Plpljp EdaTa/J) mice used in this study were purchased from Jackson Laboratory (Bar Harbor, ME). Jimpy males exhibit severe neurological phenotypes and die around 3 weeks of age due to mutations in Plpl on the Xchromosome. The colony was maintained by breeding heterozygous females, which lack a phenotype, to wild-type males to generate affected jimpy males. Mice were housed under a temperature-controlled environment, 12-h light-dark cycle with ad libitum access to water and tips or toes at two loci: 1) the jimpy mutation (NM_011123.4:c.623-2A>G) in Plp1 intron 4, which causes skipping of exon 5 and a truncated PLP protein and 2) the complex indel in Plpl exon 3 from dual cutting of CRISPR/spCas9 sgRNAs in “CR-impy” mice (c.[242_318del; 328_330del]). This "knockdown" causes a frameshift in Plpl, a premature stop codon in exon 4, and is predicted to cause nonsense mediated decay of the transcript and loss of protein. Genotyping was performed Transnetyx, Cordova, TN).

Primers for Sanger sequencing included:

jimpy Forward: AACGCAAAGCAGCACATTTCA

jimpy Reverse: AGTGCAGCTCTGGGGTTAAT 
Plp1-targeting sgRNA design. Mouse Plpl sequence was entered into the spCas9 CRISPR sgRNA design tool at crispr.mit.edu ${ }^{46}$ and analyzed against the mm10 target genome. Plpltargeting sgRNAs were sorted based on their on-target efficiency while minimizing off-target mutations. On-target nuclease activity was confirmed for each sgRNA using the Guide-it sgRNA Screening Kit (631440, Clontech) according to the manufacturer's instructions. The following sgRNAs were tested, and sgRNAs 3 and 7 were selected for combined use in zygote studies based

Knockdown of Plp1 in jimpy zygotes using CRISPR-Cas9. Carrier female oocyte donors were on localization within the gene, proximity to each other, and ability to target $P l p 1$, including its splice isoform Dm20:

sgRNA1: CCCCTGTTACCGTTGCGCTC sgRNA2: TGGCCACCAGGGAAGCAAAG sgRNA3: AAGACCACCATCTGCGGCAA sgRNA4: GGCCTGAGCGCAACGGTAAC sgRNA5: GCCTGAGCGCAACGGTAACA sgRNA6: TCTACACCACCGGCGCAGTC sgRNA7: CCAGCAGGAGGGCCCCATAA sgRNA8: GAAGGCAATAGACTGACAGG administered 5 IU pregnant mare's serum gonadotropin by intraperitoneal injection (G4877, Sigma-Aldrich), followed by 2.5 IU human chorionic gonadotropin (GC10, Sigma-Aldrich) 48 
hours later. These superovulated females were mated to wild-type males. Zygotes were harvested in FHM medium (MR-025 Sigma-Aldrich) with 0.1\% hyaluronidase (H3501, Sigma-Aldrich) and the surrounding cumulus cells were separated. The zona pellucida of each zygote was partially dissected using 0.3M sucrose (S7903, Sigma-Aldrich) in FHM as previously described ${ }^{47}$.

Zygotes were placed in 2x KSOM medium (MR-106, Sigma-Aldrich) with an equal volume of solution containing 100ng/uL sgRNA3, 100ng/uL sgRNA7 (AR01, PNAbio), and 200ng/uL spCas9 mRNA (CR01, PNAbio). Electroporation was performed in a chamber with a 1mm gap between two electrodes using an ECM 830 Square Wave Electroporation System (BTX). Electroporation parameters were set as follows: $32 \mathrm{~V}, 3 \mathrm{~ms}$ pulse duration, 5 repeats, and 100ms inter-pulse interval. Electroporated zygotes were moved to KSOM medium and then transferred into the oviducts of pseudopregnant females (CD1). Electroporation settings were optimized to achieve maximal cutting efficiency in a separate strain but resulted in a higher rate of embryo loss in our B6CBACa/J strain. Zygotes were electroporated in batches of 54, 56, and 61, which resulted in 4, 3, and 0 pups born. The 7 surviving mice were genotyped after birth and monitored daily for onset of typical jimpy phenotypes including tremors, seizures, and early death by postnatal day 21. of Plp1, denoted "CR-impy" for CRISPR frameshift-mediated knockdown of Plp1 in jimpy, showed no overt phenotype and was backcrossed for two generations to the wild-type parental strain to reduce potential off-target Cas9 cutting effects (Extended Data Fig. 1b). A colony of mice was bred to evaluate cellular, molecular, and functional phenotypes of contemporaneous isogenic wild-type, jimpy, and CR-impy male mice. Mice were monitored daily to determine lifespan with statistical significance among groups determined using the log-rank test. Additionally, animals 
surviving beyond 3 weeks were analyzed using behavioral (rotarod and open field testing for motor

performance), histology (immunostaining of the CNS for myelin proteins and electron microscopy

for myelin ultrastructure), and electrophysiology (conduction velocity of the optic nerve). Details and metadata for all mice in this study including censoring of animals in the survival analysis are found in Supplementary Fig. 1.

CRISPR on- and off-target assessment. CRISPR on- and off-target cutting efficiencies were assessed by high throughput sequencing. PCR primers were designed to encompass each guide ontarget site, as well as each top predicted off-target site from the spCas9 CRISPR sgRNA design tool at crispr.mit.edu ${ }^{46}$. Primer sequences were generated using NCBI Primer-BLAST:

\begin{tabular}{|l|l|l|l|}
\hline $\begin{array}{l}\text { PCR } \\
\text { amplicon }\end{array}$ & $\begin{array}{l}\text { Genomic } \\
\text { Location }\end{array}$ & Forward Primer & Reverse Primer \\
\hline $\begin{array}{l}\text { sgRNA } \\
\text { on-target }\end{array}$ & $\begin{array}{l}\text { Plpl } \\
\text { exon } 3\end{array}$ & TCTGTCTGTCCATGCAGGATT & GACACACCCGCTCCAAAGAA \\
\hline $\begin{array}{l}\text { sgRNA3 } \\
\text { off-target }\end{array}$ & $\begin{array}{l}\text { Intronic } \\
(\text { Shf, chr. } 2)\end{array}$ & TGGGTAGGACAGACAAAGGA & ACAAGGTCATACACACTCAGGC \\
\hline $\begin{array}{l}\text { sgRNA7 } \\
\text { off-target }\end{array}$ & $\begin{array}{l}\text { Intergenic } \\
\text { (chr. 6) }\end{array}$ & ACGACCAGACTGCAGATGAAA & TACCCCCAGCACTTGACGAT \\
\hline
\end{tabular}

Tails were added to each primer sequence:

Reverse: AGTTCAGACGTGTGCTCTTCCGATCT

PCR amplification was performed using the KAPA HiFi HotStart ReadyMix (07958935001, Roche) to minimize PCR-based error. Libraries were prepared by adding unique indices by PCR using KAPA HiFi HotStart ReadyMix. All libraries were pooled evenly and quantified using NEBNext ${ }^{\circledR}$ Library Quant Kit for Illumina ${ }^{\circledR}($ E7630, New England Biolabs) then denatured and diluted per Illumina's MiSeq instructions. 250bp paired-end sequencing was performed using an 
Illumina MiSeq at the Case Western Reserve University School of Medicine Genomics Core Facility. Reads were compared against the consensus sequence and CRISPR-induced indel percentages were determined using the OutKnocker tool at outknocker.org ${ }^{48}$.

Video recording of mouse phenotypes. All recording was performed using video recording function on an iPhone (Apple). Videos were color corrected, stabilized, and trimmed to a discrete range using iMovie (Apple). Videos were collated and converted to MP4 format using Adobe After Effects.

Immunohistochemistry. Mice were anesthetized with isoflurane and sacrificed by transcardial perfusion with PBS followed by 4\% paraformaldehyde (PFA; 15710, Electron Microscopy Sciences). Tissue was harvested and placed in $4 \%$ PFA overnight at $4^{\circ} \mathrm{C}$. Samples were rinsed with PBS, equilibrated in 30\% sucrose, and frozen in Tissue-Tek® Optimum Cutting Temperature

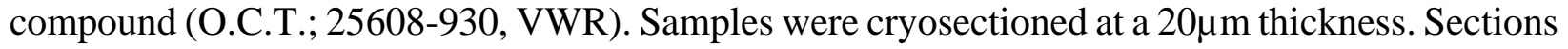
were washed in phosphate-buffered saline (PBS) and incubated overnight in antibody solution containing 2.5\% normal donkey serum (NDS; 017-000-121, Jackson Labs) and $0.25 \%$ Triton X100 (Sigma: T8787). For MBP immunohistochemistry, sections were post fixed in methanol at $20^{\circ} \mathrm{C}$ for 20 minutes followed by overnight incubation in a PBS based primary antibody solution containing $0.1 \%$ Saponin and $2.5 \%$ normal donkey serum. Sections were stained using the following antibodies at the indicated concentrations or dilutions: mouse anti-MBP $(2 \mu \mathrm{g} / \mathrm{mL}$, 808401, Biolegend), rabbit anti-MyRF antibody (1:500; kindly provided by Dr. Michael Wegner), rat anti-PLP (1:500; Lerner Research Institute Hybridoma Core, Cleveland, OH), goat anti-Sox10

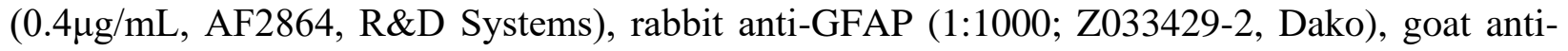


IBA1 (0.1mg/mL, ab5076, Abcam), anti-phospho-neurofilament (2ug/ml, 801601, BioLegend), and rabbit anti-ASO (1:2500; Ionis Pharmaceuticals). Secondary immunostaining was performed with Alexa Fluor ${ }^{\circledR}$ antibodies (ThermoFisher) used at $1 \mathrm{ug} / \mathrm{ml}$. Nuclei were identified using 100ng/ml DAPI (D8417, Sigma). Stained sections were imaged using the Operetta ${ }^{\circledR}$ High Content section images and a Leica Sp8 confocal microscope or a Leica DMi8 inverted microscope with Leica Application Suite X software for all other immunohistochemical imaging. To quantify MyRF staining, MyRF+ cells were counted along the length of the whole corpus callosum from medial sagittal sections from three animals per genotype. A one-way ANOVA with correction for multiple comparisons or a Welch's t-test was performed to determine statistical significance across genotypes.

qRT-PCR. Mice were euthanized using isoflurane overdose. Different brain regions (cerebral cortex, cerebellum, and brainstem) were harvested. Each brain region was split in two and half was used for RNA quantification using qRT-PCR, the other for western blot analysis (see below). TRI Reagent (R2050-1-200, Zymo Research) was separately added to tissue and samples were homogenized using Kontes Pellet Pestle Grinders (KT749520-0000, VWR). RNA was extracted using the RNeasy Mini Kit (74104, Qiagen) according to the manufacturer's instructions. Reverse transcription was performed using the iScript cDNA Synthesis Kit (1708891, Biorad) with 1 $1 \mu \mathrm{g}$ of RNA per reaction. Real-Time PCR was then performed on an Applied Biosystems 7300 Real-time PCR system with 10ng cDNA per sample in quadruplicate using Taqman gene expression master mix (4369016, ThermoFisher) and the following pre-designed Taqman gene expression assays (4351370, ThermoFisher): Plp1 (Mm01297210_m1), Mbp (Mm01266402_m1) and Actb 
(Mm00607939_s1) (endogenous control). Expression values were normalized to Actb and to wildtype samples (for CRISPR cohort) or wild-type untreated samples (for ASO-treated wild-type cohort). Graphpad Prism software was used to perform a one-way ANOVA with Tukey correction or a one-way ANOVA with Dunnett's correction for multiple comparisons to determine statistical significance across genotypes or ASO treatments, respectively.

Protein quantification and western blot. Tissues were obtained as described above. Protein lysis buffer consisting of RIPA buffer (R0278, Sigma), cOmplete ${ }^{\mathrm{TM}}$ Mini EDTA-free Protease Inhibitor Inhibitor Cocktail 2 (P5726, Sigma), and BGP-15 (B4813, Sigma) was added to each sample. Tissue was homogenized using Dounce Tissue Grinders (D8938, Sigma). Lysate was separated by centrifugation at $17000 \mathrm{~g}$ for 15 minutes at $4^{\circ} \mathrm{C}$. A BCA standard curve was generated using the Pierce BCA Protein Assay Kit (23225, Thermo Scientific) and used to samples to an equivalent protein concentration. Equal amounts of sample were run on a NuPAGE 4-12\% Bis-Tris Protein gel (NP0335BOX or NP0329BOX, Thermo Fisher), then electrophoretically transferred to a PVDF membrane (LC2002, Invitrogen or 926-31097, Li-Cor). The membrane was blocked with $5 \%$ milk in TBS-T for an hour, then hybridized with mouse anti-MBP antibody $(1 \mu \mathrm{g} / \mathrm{mL} ; 808401$, Biolegend) or rat anti-PLP antibody (1:1000; Lerner Research Institute Hybridoma Core, Cleveland, $\mathrm{OH}$ ) overnight at $4^{\circ} \mathrm{C}$. Blots were then washed in TBS-T and incubated in goat antimouse HRP (1:2500, 7076, Cell Signaling), goat anti-rat HRP (1:2500, 7077, Cell Signaling), or IRDye secondaries (1:20000, 925, Li-Cor). Each sample was normalized to B-actin using HRPconjugated mouse anti-B-actin (1:10000, A3854-200UL, Sigma-Aldrich). All secondary antibodies were incubated for one hour at room temperature. Blots were analyzed with the 
Odyssey® Fc imaging system (Li-Cor). Graphpad Prism software was used to perform a one-way ANOVA with Tukey correction or a one-way ANOVA with Dunnett's correction for multiple comparisons to determine statistical significance across genotypes or ASO treatments, respectively. Raw annotated images of full western blots are provided in Supplementary Figs. 2 and 4.

Electron microscopy and toluidine blue staining. Mice were anesthetized with isoflurane and rapidly euthanized. Tissue was collected after transcardial perfusion with PBS followed by $4 \%$ paraformaldehyde and 2\% glutaraldehyde (16216, Electron Microscopy Sciences) in 0.1M sodium cacodylate buffer, pH 7.4 (11652, Electron Microscopy Sciences), except for 6 month optic nerve samples which were placed directly into fixative without perfusion. Samples were post-fixed with $1 \%$ osmium tetroxide (19150, Electron Microscopy Sciences) and stained with $0.25 \%$ uranyl acetate (22400, Electron Microscopy Sciences), en bloc. Samples were dehydrated using increasing concentrations of ethanol, passed through propylene oxide, and embedded in Eponate 12 ${ }^{\mathrm{TM}}$ epoxy resin (18012, Ted Pella). Silver-colored sections were prepared (Leica EM UC6), placed on 300 mesh nickel grids (T300-Ni, Electron Microscopy Sciences), stained with 2\% uranyl acetate in $50 \%$ methanol, and stained with lead citrate (17800, Electron Microscopy Sciences). Sections were imaged using a FEI Tecnai Spirit electron microscope at $80 \mathrm{kV}$. Myelinated axons were manually counted from the sections made on the middle part of the nerve lengthwise and at least three areas across the optic nerve diameter using Adobe Photoshop (Adobe Systems). Graphpad Prism software was used to perform a one-way ANOVA with Tukey correction to determine significance across genotypes. Toluidine Blue (22050, Electron Microscopy Sciences) stained $1 \mu \mathrm{m}$ sections were prepared from same epoxy resin embedded samples above and 
visualized with a light microscope (Zeiss Axioskop2) using plan-NEOFLUAR 100X 1.30 oil objective lens and images were captured using a Scion 1394 color camera with ImageJ software.

Optic nerve electrophysiology. Mice were deeply anesthetized with isoflurane and euthanized. Each eye with its attached optic nerve was dissected and placed in Ringer's solution consisting of $129 \mathrm{mM} \mathrm{NaCl}$ (BP358-212, Fisher Scientific), 3mM KCl (BP366-500, Fisher Scientific), 1.2mM $\mathrm{NaH}_{2} \mathrm{PO}_{4}$ (1-3818, J. T. Baker Chemical), 2.4mM CaCl 2 (C79-500, Fisher Scientific), 1.3mM $\mathrm{MgSO}_{4}$ (M2643, Sigma), 20mM NaHCO 3 (S233-500, Fisher Scientific), 3mM HEPES (H3375, Sigma), 10mM glucose (G5767, Sigma), oxygenated using a 95\% $\mathrm{O}_{2} / 5 \% \mathrm{CO}_{2}$ gas mixture. Each nerve was carefully cleaned, transected behind the eye, at the optic chiasm, and allowed to recover for one hour in oxygenated Ringer's solution at room temperature $\left(22-24^{\circ} \mathrm{C}\right)$. Each end of the nerve was set in suction electrodes, pulled from polyethylene tubing (PE-190, BD Biosciences). Monophasic electrical stimuli were applied to the proximal end of the nerve and recordings were captured at the distal end. The recovery of the response was monitored every $20 \mathrm{~min}$ for one hour, and only fully recovered samples were subjected to additional stimuli. Stimuli were generated with a S48 stimulator (Grass Technologies) and isolated from ground with PSIU6B unit (Grass Technologies). Supra-threshold stimulus was determined using $30 \mu$ s stimulus duration. The response was amplified 100X with P15D preamplifier (Grass Technologies), monitored with oscilloscope (V1585, Hitachi), digitized with Digidata1550A (Axon Instruments) and recorded using $50 \mathrm{kHz}$ sampling rate with AxoScope software (Axon Instruments). The distance between the electrodes was measured and used to calculate the conduction velocity of the compound action potential (CAP) peaks at their latency. Recorded signals were analyzed using AxoScope software. 
Open Field Testing. Locomotion was assessed by open field testing. Animals were placed in the center of a 20 -inch by 20 -inch square box and all movements were captured for a total of five minutes using ANY-maze software version 5.0 (Stoelting Co). Total distance traveled was reported for each animal. Graphpad Prism software was used to perform a one-way ANOVA with Tukey correction or a one-way ANOVA with Dunnett's correction for multiple comparisons to determine statistical significance across genotypes or ASO treatments, respectively.

Rotarod Testing. Motor performance was assessed using a Rota Rod Rotomax 5 (Columbus Instruments) with a $3 \mathrm{~cm}$ diameter rotating rod. Immediately prior to testing animals were trained at a constant speed of 4 rounds per minute (rpm) for a total of two minutes. Testing began at $4 \mathrm{rpm}$ with an acceleration of $0.1 \mathrm{rpm} / \mathrm{s}$. Time to fall was recorded from three independent trials, and the were allowed to rest for at least five minutes. Graphpad Prism software was used to perform a oneway ANOVA with Tukey correction or a one-way ANOVA with Dunnett's correction for multiple comparisons to determine statistical significance across genotypes or ASO treatments, respectively.

Generation of iPSCs. Tail tips ( $2 \mathrm{~mm}$ piece from 8 day old CR-impy mice) were bisected, placed on Nunclon- $\Delta$ 12-well plates (150628, ThermoFisher), and covered with a circular glass coverslip (12-545-102; Fisher Scientific) to maintain tissue contact with the plate and enable fibroblast outgrowth. Tail-tip fibroblasts were cultured in 'fibroblast medium' consisting of DMEM (11960069, ThermoFisher) with 10\% fetal bovine serum (FBS; 16000044, ThermoFisher), 1x nonessential amino acids (11140050, ThermoFisher), 1x Glutamax (35050061, ThermoFisher), and 

streptomycin (15070-063, ThermoFisher). Medium was changed every day for the first 3 days and then every other day. medium, and allowed to equilibrate overnight. The following day medium was removed and replaced with an equal volume of pHAGE2-TetOminiCMV-STEMCCA-W-loxp lentivirus pLVX-Tet-On-Puro (632162, Clontech) lentivirus supplemented with $8 \mu \mathrm{g} / \mathrm{mL}$ polybrene (107689, according to manufacturer's instructions. Three hours later lentivirus medium was removed and replaced with fibroblast medium supplemented with $2 \mu \mathrm{g} / \mathrm{ml}$ doxycycline (631311, Clontech). The and $10^{3}$ units/ml LIF. After 3 days fibroblasts were lifted using Accutase and seeded on Nunclon$\Delta$ plates, atop a feeder layer of irradiated mouse embryonic fibroblasts (iMEFs; produced in-house) previously plated at $1.7 \times 10^{4}$ cells $/ \mathrm{cm}^{2}$ on $0.1 \%$ gelatin $(1890$, Sigma) coated Nunclon- $\Delta$ plates in “pluripotency medium” consisting of Knockout DMEM (10829-018, ThermoFisher), 5\% FBS, 15\% knockout replacement serum (10828028, ThermoFisher), 1x Glutamax, 1x nonessential amino acids, $0.1 \mathrm{mM}$ 2-mercaptoethanol, and $10^{3}$ units/ml LIF (LIF; ESG1107, EMD Millipore) supplemented with $2 \mu \mathrm{g} / \mathrm{ml}$ doxycycline. Medium was changed every day until iPSC colonies 
began to emerge. Individual colonies were picked and dissociated in accutase and were individually plated in single wells of Nunclon- $\Delta$ 12-well plates, atop an iMEF feeder layer in pluripotency medium supplemented with $2 \mu \mathrm{g} / \mathrm{ml}$ doxycycline. Clones were further expanded, with daily medium changes. iPSC colonies were stained for pluripotency markers and karyotyped at the seventh passage after derivation (Cell Line Genetics; Madison, WI). CR-impy iPSCs were derived and characterized for this study (line identifier jpCR100.1). Isogenic comparator jimpy (line identifier i.jp-1.6) and wild-type (line identifier i.wt-1.0) iPSC lines were described and

Generation of iPSC-derived OPCs. iPSCs were differentiated to OPCs as previously described characterized separately ${ }^{22}$. Genotypes of iPSCs were re-verified prior to use. IV (17104019, ThermoFisher) and dissociated with either 0.25\% Typsin-EDTA or Accutase and seeded at $7.8 \times 10^{4}$ cells/cm2 on Costar Ultra-Low attachment 6-well plates (3471, Corning). Cultures were then directed through a stepwise differentiation process to generate pure populations of OPCs. OPCs were maintained in "OPC medium” consisting of DMEM/F12 (11320082, ThermoFisher), 1x N2 supplement (AR009, R\&D Systems), 1x B-27 without vitamin A supplement (12587-010, ThermoFisher), and 1x Glutamax (collectively "N2B27 medium”), supplemented with $20 \mathrm{ng} / \mathrm{mL}$ fibroblast growth factor 2 (FGF2; 233-FB, R\&D Systems) and 20 ng/mL platelet-derived growth factor-AA (PDGF-AA; 221-AA, R\&D Systems). Medium was changed every other day. For characterization of purity, iPSC-derived OPCs from all genotypes 

each genotype were plated in parallel onto Nunclon- $\Delta$ 96-well plates (150628, ThermoFisher) that were first coated with $100 \mu \mathrm{g} / \mathrm{mL}$ poly(L-ornithine) (P3655, Sigma), followed by $10 \mu \mathrm{g} / \mathrm{ml} \mathrm{laminin}$ solution (L2020, Sigma). For the oligodendrocyte differentiation assay, 25,000 cells were seeded per well in media that consisted of DMEM/F12 (11320082, ThermoFisher), 1x N2 supplement (AR009, R\&D Systems), 1x B-27 without vitamin A supplement (12587-010, ThermoFisher), and 1x Glutamax, supplemented with T3 (40ng/ml), Noggin (100ng/ml), cAMP (10uM), IGF $(100 \mathrm{ng} / \mathrm{ml})$ and NT3 (10ng/ml). All plates were incubated at $37^{\circ} \mathrm{C}$ and $5 \% \mathrm{CO}_{2}$ for 3 days. Cells were immunostained using for myelin protein markers. Eight fields were captured per well and the total number of MBP+ cells were quantified for each cell line. Graphpad Prism software was used to perform a one-way ANOVA with Tukey correction for multiple comparisons to determine

Immunocytochemistry. Cells were fixed with $4 \%$ paraformaldehyde (PFA) in phosphate buffered saline (PBS). After fixation, cells were permeabilized with $0.2 \%$ Triton X-100 in PBS followed by blocking in $10 \%$ donkey serum in PBS. Cells were stained overnight at $4{ }^{\circ} \mathrm{C}$ with the following statistical significance across genotypes. primary antibodies diluted in blocking solution: rat anti-MBP (1:100; ab7349, Abcam), rat antiPLP (1:5000; Lerner Research Institute Hybridoma Core, Cleveland, OH), goat anti-Sox10 (2 $\mu \mathrm{g} / \mathrm{mL} ;$ AF2864, R\&D Systems), rabbit anti-Olig2 (1:1000; 13999-1-AP, ProteinTech), rabbit

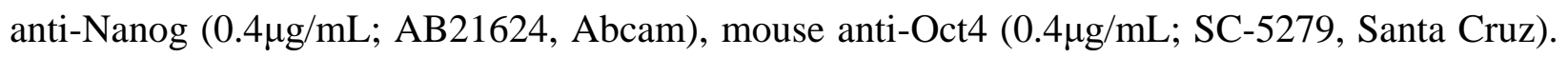
For secondary immunostaining, Alexa Fluor ${ }^{\circledR}$ antibodies (ThermoFisher) were used at 1ug/ml, and DAPI (100ng/mL, D8417, Sigma) was used at to identify nuclei. 
ASO design and characterization. Second generation ASOs were designed to target mouse Plpl. ASOs consisted of 20-mer nucleotide sequences with 2'-O-methoxyethyl (MOE) modifications and a mixed backbone of phosphorothioate and phosphodiester internucelotide linkages.

ASOs were screened for efficacy in primary E16 cortical cultures, as previously described ${ }^{35}$. mRNA was normalized to total RNA measured with the Quant-iTTM RiboGreen ${ }^{\circledR}$ RNA reagent. ASOs that efficiently reduced Plpl mRNA were selected for in vivo screening and tolerability studies. intracerebroventricular (ICV) injection and Plpl mRNA levels were measured by RT-qPCR in cortex and spinal cord tissue after 2 weeks. ASOs with greater than 90\% Plpl mRNA reduction were selected for further characterization. These were administered to mice via single $300 \mu \mathrm{g} \mathrm{ICV}$ bolus injection to test for efficacy and tolerability, as measured by markers of glial cell activation, 8 weeks post-ICV. Levels of Plpl mRNA as well as markers of astro- or micro-glial activation, Gfap, Aifl, and CD68, were assessed by RT-qPCR using the following custom primer/probe sets (Integrated DNA Technologies):

\begin{tabular}{|l|l|l|l|}
\hline Gene & Forward primer & Reverse primer & Probe (5'FAM; 3'TAMRA) \\
\hline Plp1 & CTGATGCCAGAATGTATGGTGT & AGGTGGAAGGTCATTTGGAAC & TGCAGATGGACAGAAGGTTGGAGC \\
\hline Gfap & GAAACCAGCCTGGACACCAA & TCCACAGTCTTTACCACGATGTTC & TCCGTGTCAGAAGGCCACCTCAAGA \\
\hline Aif1 & TGGTCCCCCAGCCAAGA & CCCACCGTGTGACATCCA & AGCTATCTCCGAGCTGCCCTGATTGG \\
\hline Cd68 & TGGCGGTGGAATACAATGTG & GATGAATTCTGCGCCATGAA & CCTCCCACAGGCAGCACAGTGG \\
\hline
\end{tabular}


Immunohistochemical staining was used to assess morphology of astrocytes (rabbit polyclonal antibody, DAKO) and microglia (rabbit polyclonal antibody, WAKO) in formalin-fixed, paraffin embedded brain and spinal cord sections. Plpl ASO.a (intron 5) and ASO.b (3' UTR) were selected for use in jimpy mice, as well as a control ASO with no known murine target.

Therapeutic application of ASOs to postnatal mice. Male pups from crosses between jimpy mutation carrier females and wild-type males were administered 30ug of either Plpl-targeting ASOs Plp1.a, Plp1.b, a control non-targeting ASO, or left untreated. ASOs were administered using a Hamilton 1700 gastight syringe (7653-01, Hamilton Company) by ICV injection to cryoanesthetized mice. The needle was placed between bregma and the eye, 2/5 the distance from bregma, and inserted to a depth of $2 \mathrm{~mm}$ according to published protocols ${ }^{49}$. A total volume of $2 \mathrm{uL}$ was administered to the left ventricle. Mice were allowed to recover on a heating pad and subsequently reintroduced to the mother.

Mice were genotyped at approximately postnatal day 7 and monitored daily for onset of typical jimpy phenotypes including tremors, seizures, and early death by 3 weeks of age. Lifespan was determined for each animal with statistical significance among groups determined using the logrank test. All mice surviving to a pre-determined endpoint of 8 months of age were sacrificed for histological analysis. Additionally, animals surviving beyond 3 weeks were analyzed using behavioral (rotarod and open field testing for motor performance). Details and metadata for all mice in this study are found in Supplementary Fig. 3. 
a

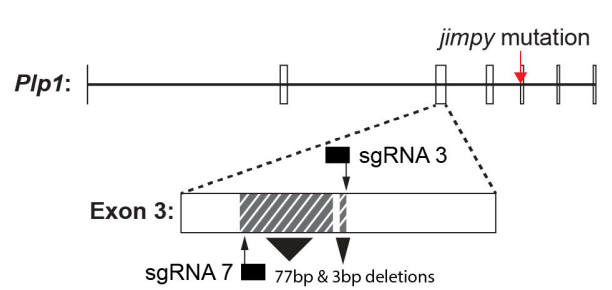

b

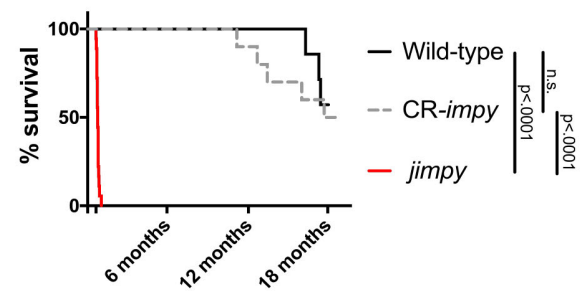

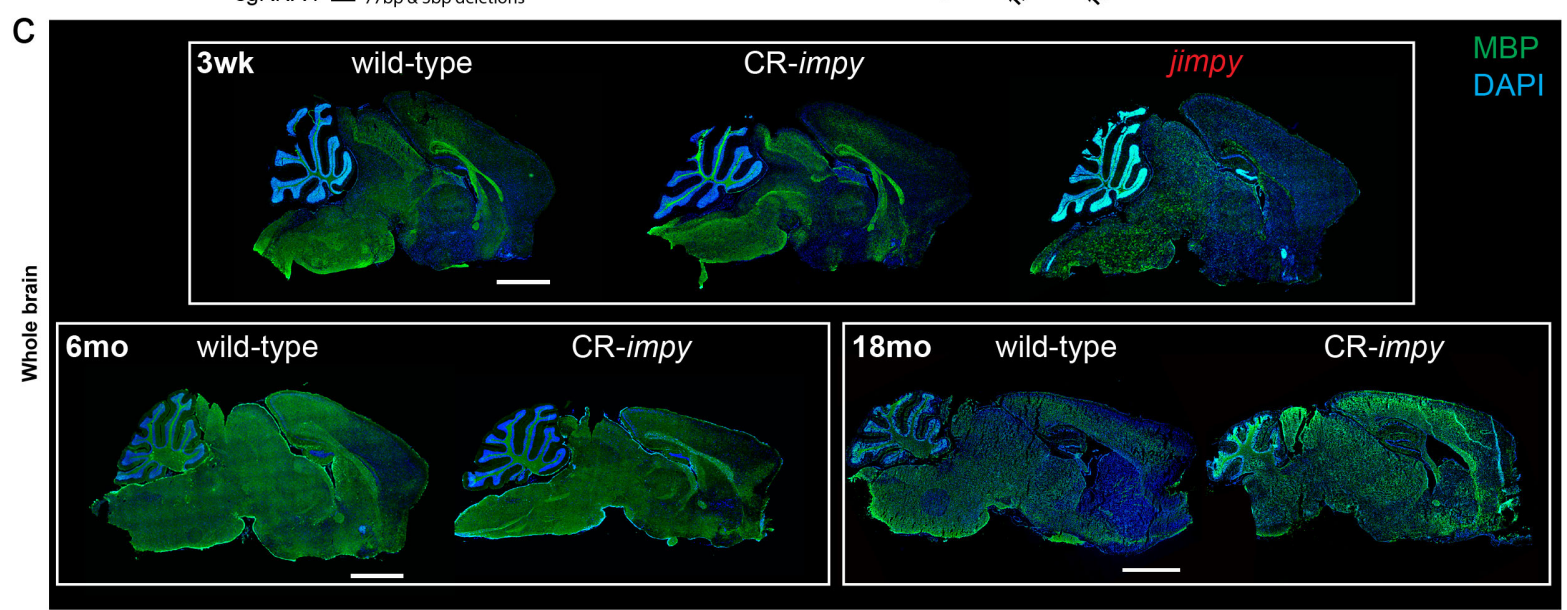
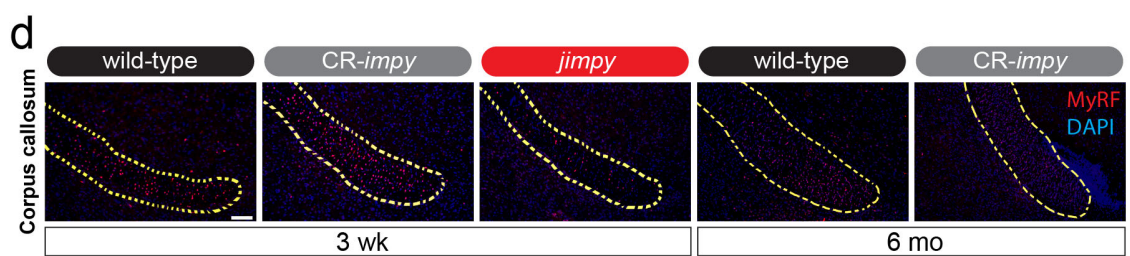

e
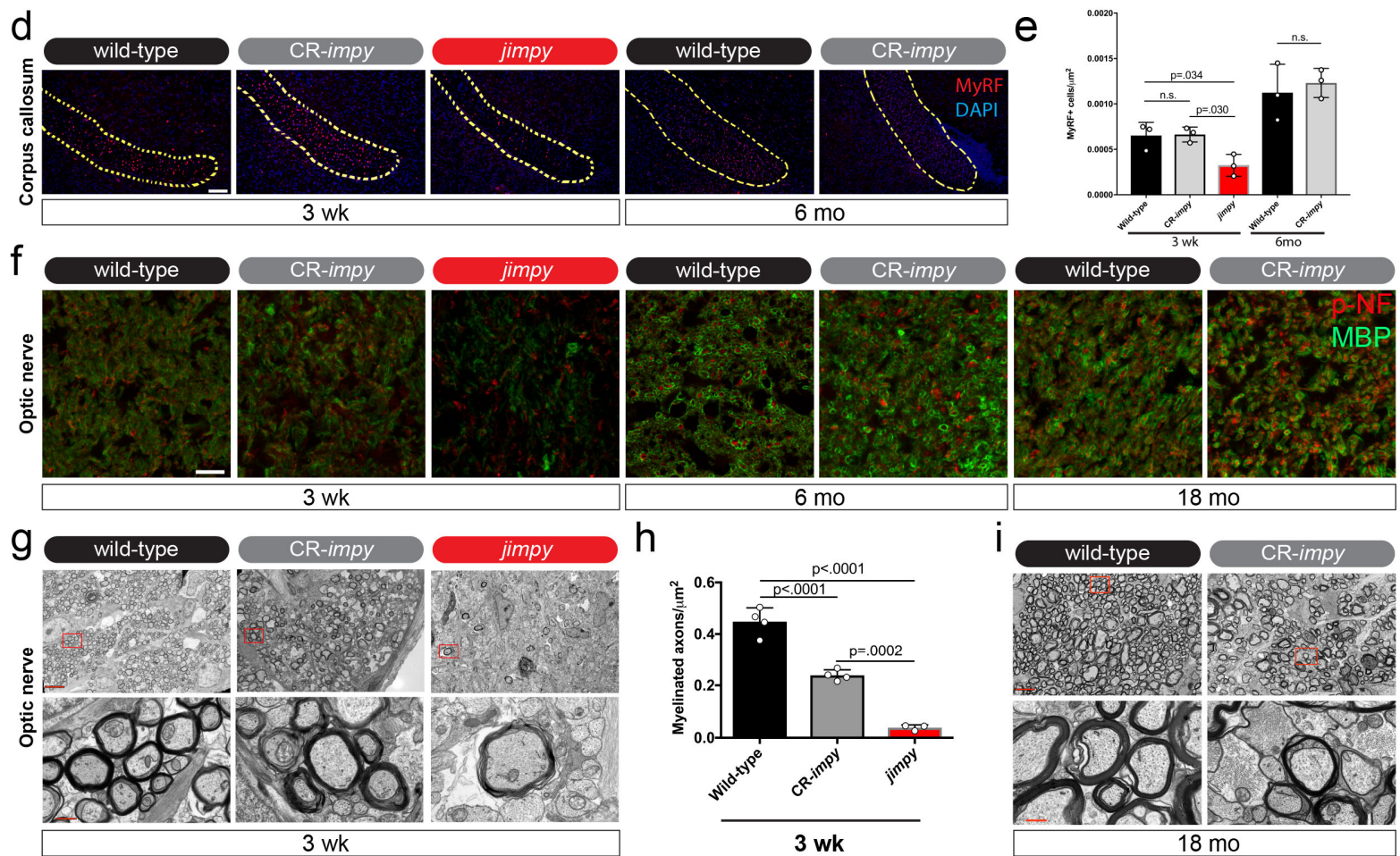

Fig. 1 | Prevention of PMD and rescue of lifespan by CRISPR-mediated knockdown of Plp1 in the germline of jimpy mice. 
3 and 7) were utilized and their DNA binding sites are indicated by solid black bars and their predicted cutting sites by black arrows. The complex, frameshift deletion of 80 base-pairs of deleted sequence within exon 3 in the CR-impy mice is shown by two grey hashed boxes (see Extended Data Fig. 1 for more detail and sequence traces).

b, Kaplan-Meier plot comparing lifespan of contemporaneous wild-type, jimpy, and CR-impy mouse cohorts. $\mathrm{n}=25,18$, and 23 starting animals in the wild-type, jimpy, and CR-impy cohorts, respectively (see Supplementary Fig. 1 for metadata of every animal in this study including censoring of animals for molecular and functional studies at pre-determined time points). p-values calculated using the log-rank test between cohorts.

c, Representative immunohistochemical images of whole-brain sagittal sections showing MBP+ oligodendrocytes (green) and total DAPI+ cells (blue) in wild-type, CR-impy, and jimpy mice at 3 weeks, 6 months, and 18 months of age. Scale bar, $2 \mathrm{~mm}$.

d, Representative sagittal immunohistochemical images of the rostral end of the corpus collosum showing MyRF+ oligodendrocytes (red) and total DAPI+ cells (blue) in wild-type, CR-impy, and jimpy mice at 3 weeks, 6 months, and 18 months of age. Scale bar, $100 \mu \mathrm{m}$.

e, Quantification of MyRF+ oligodendrocytes in the corpus callosum at 3 weeks and 6 months of age for each genotype. $\mathrm{n}=3$ mice per genotype at each time point. Error bars show mean \pm standard deviation. p-values calculated using ANOVA with Tukey correction for multiple comparisons at 3 weeks and Welch's t-test at 6 months.

f, Representative confocal immunohistochemical images of optic nerve cross sections showing $\mathrm{MBP}+$ oligodendrocytes (green) and phospho-neurofilament+ intact axons (red) in wild-type, CRimpy, and jimpy mice at 3 weeks, 6 months, and 18 months of age. Scale bar, $20 \mu \mathrm{m}$.

g, Representative electron micrograph images showing myelination in optic nerve cross sections in wild-type, CR-impy, and jimpy mice at 3 weeks of age. Lower panel is a higher magnification of red boxed area in the upper panel. Upper panel scale bar, $5 \mu \mathrm{m}$ and lower panel scale bar is $0.5 \mu \mathrm{m}$.

$\mathbf{h}$, Quantification of the number of myelinated axons in optic nerves of each genotype at postnatal week 3. $\mathrm{n}=4$ mice for wild-type and CR-impy and $\mathrm{n}=3$ mice for and jimpy genotypes. Error bars show mean \pm standard deviation. p-values calculated using ANOVA with Tukey correction for multiple comparisons.

i, Representative electron micrograph images of myelination in optic nerve cross sections in wildtype and CR-impy mice at 18 months of age. Lower panel is a higher magnification of red boxed area in the upper panel. Upper panel scale bar, $5 \mu \mathrm{m}$ and lower panel scale bar is $0.5 \mu \mathrm{m}$. 

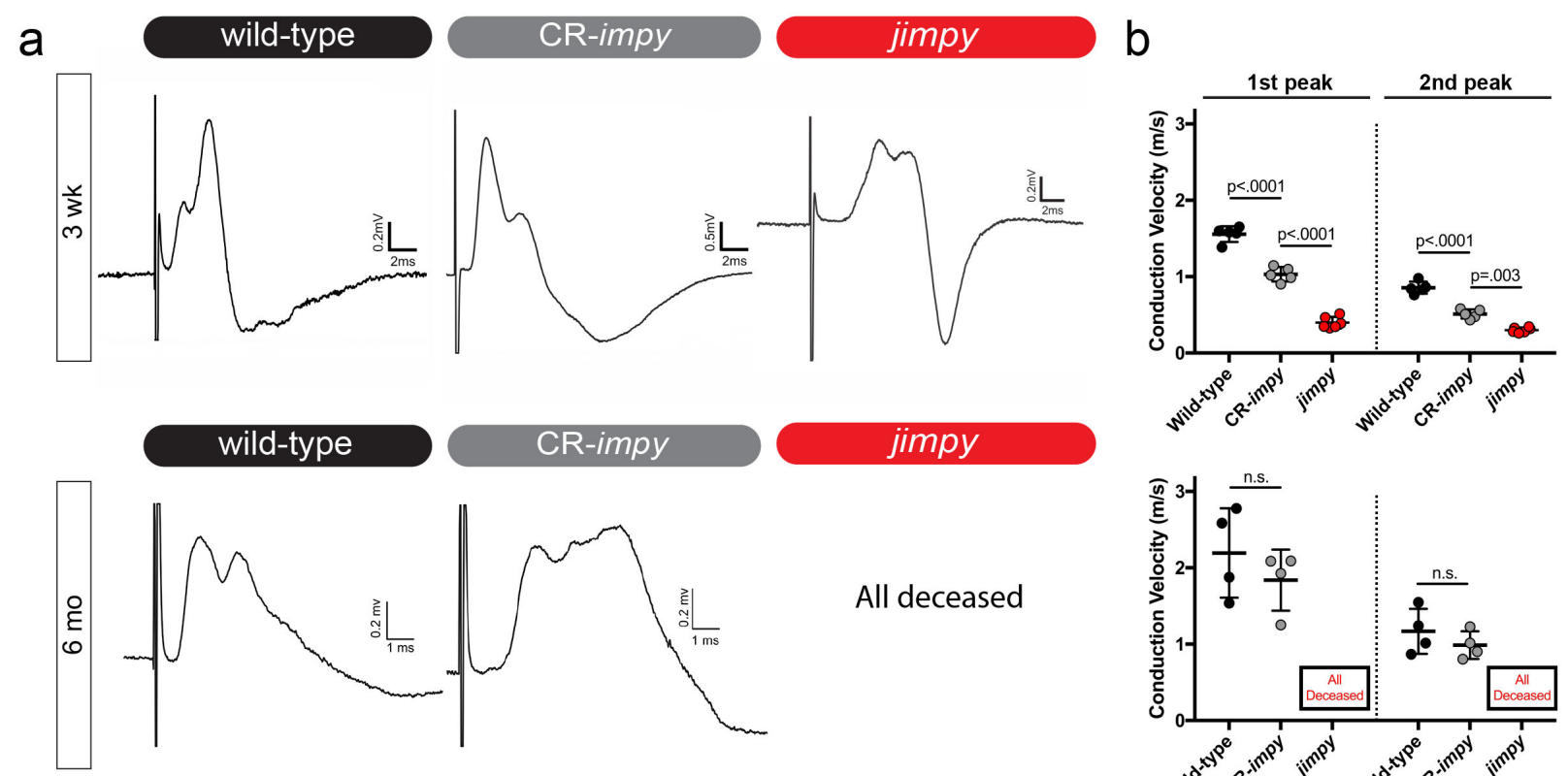

C
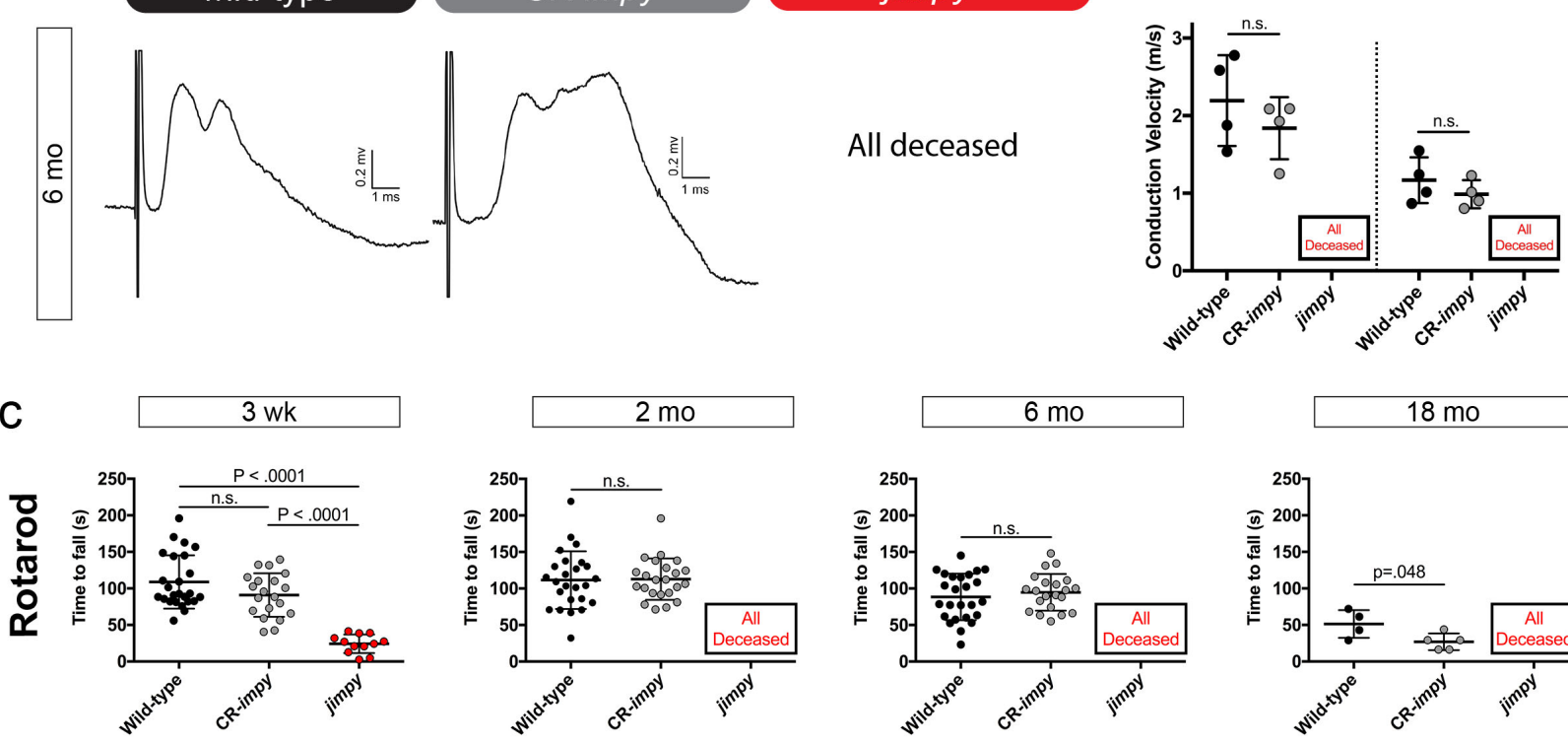

d
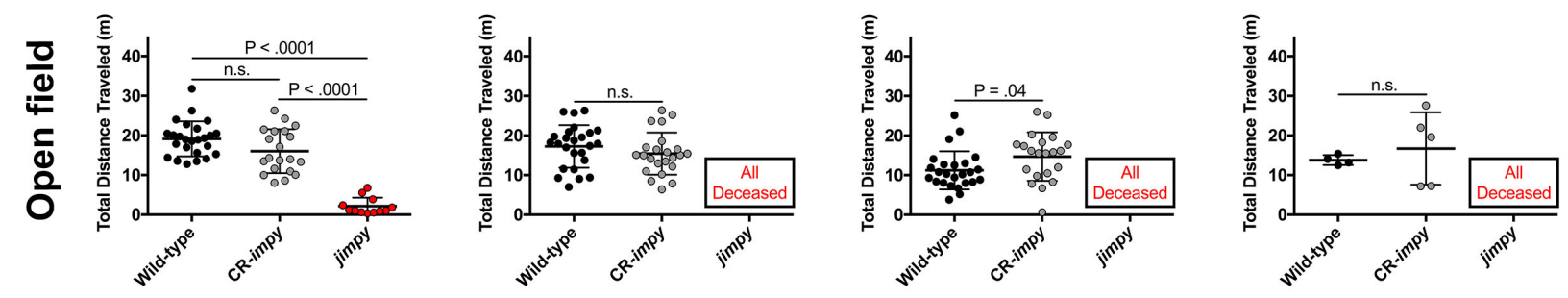

Fig. 2 | CRISPR-mediated knockdown of Plp1 in jimpy mice restores myelin function and motor phenotypes.

a, Representative electrophysiology optic nerve conduction traces from wild-type, CR-impy, jimpy mice at 3 weeks and 6 months of age. weeks and 6 months of age. Each point represents an individual biological replicate (optic nerves from separate mice) with $\mathrm{n}=5,5$, and 6 wild-type, jimpy, and CR-impy mice, respectively, at the 3 week time point and $n=4$ wild-type and CR-impy mice each at the 6 month time point. Error bars show mean \pm standard deviation. p-values calculated using one-way ANOVA with Tukey 
correction for multiple comparisons at 3 weeks and two-way, unpaired t-test at 6 months. c, Comparison of motor function and coordination of wild-type, CR-impy, and jimpy mice at 3 weeks ( $\mathrm{n}=25,20$, and 12 wild-type, jimpy, and CR-impy mice), 2 months ( $\mathrm{n}=25$ and 23 wild-type and CR-impy mice), 6 months ( $\mathrm{n}=25$ and 21 wild-type and CR-impy mice), and 18 months of age ( $\mathrm{n}=4$ and 5 wild-type and CR-impy mice) by accelerating rotarod performance. Individual data points represent the mean time to fall of three separate trials for each biological replicate (separate mice). Error bars show mean \pm standard deviation. p-values calculated using one-way ANOVA with Tukey correction for multiple comparisons at 3 weeks or two-way, unpaired t-test at later time points. See Supplementary Fig. 1 for raw data values. d, Comparison of locomotor activity of wild-type, CR-impy, and jimpy mice at 3 weeks $(\mathrm{n}=25,20$, and 12 wild-type, jimpy, and CR-impy mice), 2 months (n= 25 and 23 wild-type and CR-impy mice), 6 months ( $\mathrm{n}=25$ and 21 wild-type and CR-impy mice), and 18 months of age ( $\mathrm{n}=4$ and 5 wild-type and CR-impy mice) by open field testing. Individual data points represent total distance traveled for each biological replicate (separate mice). Error bars show mean \pm standard deviation. p-values calculated using one-way ANOVA with Tukey correction for multiple comparisons at 3 weeks or two-way, unpaired t-test at later time points. See Supplementary Fig. 1 for raw data values. 

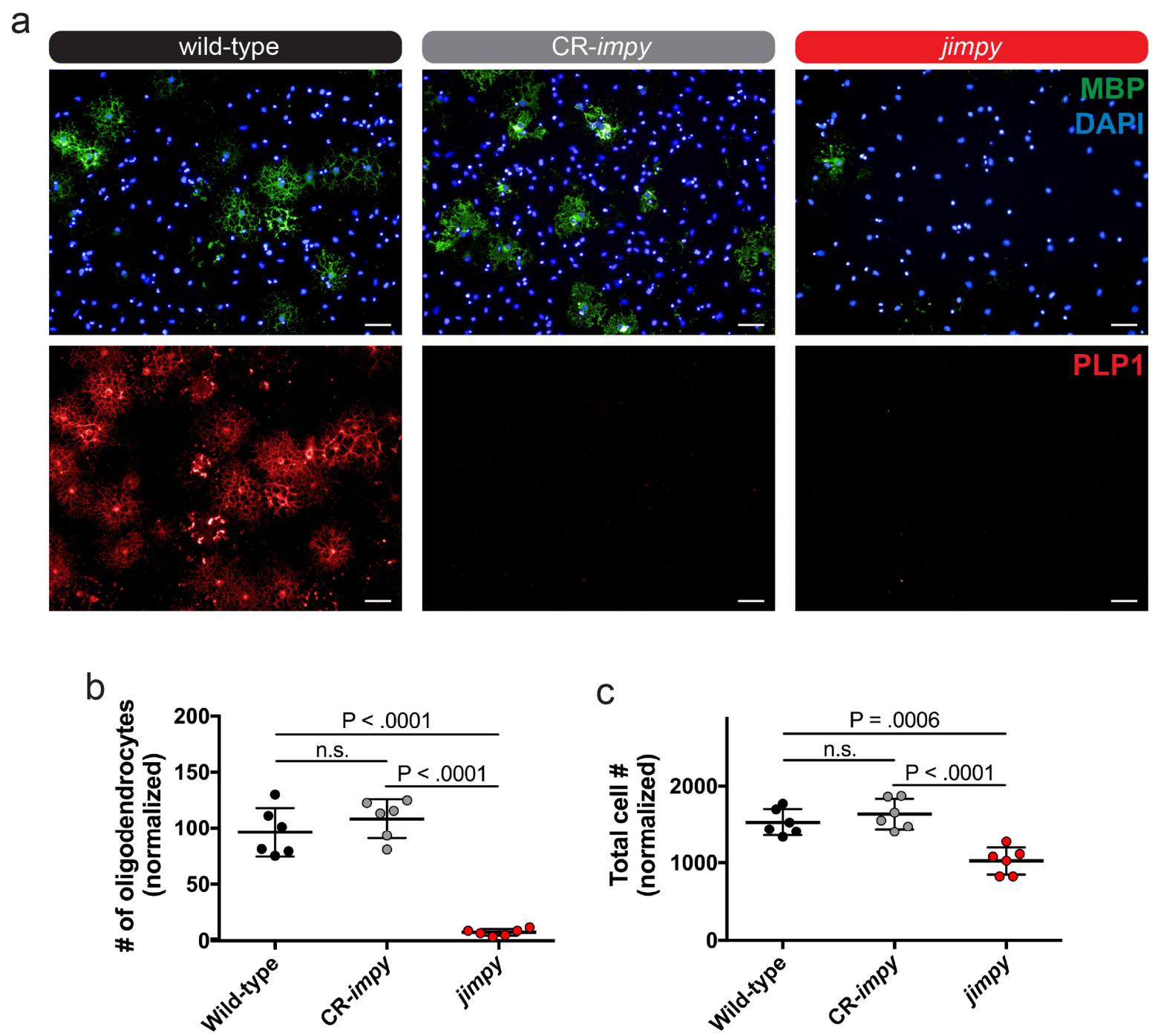

801

803

804

805

806

807

808

809

810

811

812

813

814

815

Fig. 3 | CRISPR-mediated knockdown of Plp1 in jimpy OPCs rescues survival of differentiating oligodendrocytes in vitro.

a, Representative immunocytochemistry images of MBP + oligodendrocytes and PLP + oligodendrocytes from wild-type, CR-impy, and jimpy iPSC-derived OPCs differentiated in vitro for 3 days. Top and bottom rows are the same field but channels are separated for clarity. Note the PLP1 antibody detects a C-terminal peptide sequence not present in jimpy and therefore absence of staining simply serves as validation of jimpy genotype but not quantification of total PLP1 protein (for which there are no validated N-terminal antibodies for immunostaining). Scale bar, $50 \mu \mathrm{m}$.

b-c, Quantification of MBP+ oligodendrocytes (b) and total DAPI+ cells (c). Error bars show mean \pm standard deviation. $n=6$ technical replicates (single cell line per genotype with 6 separate wells scored). p-values calculated using one-way ANOVA with Tukey correction for multiple comparisons. 

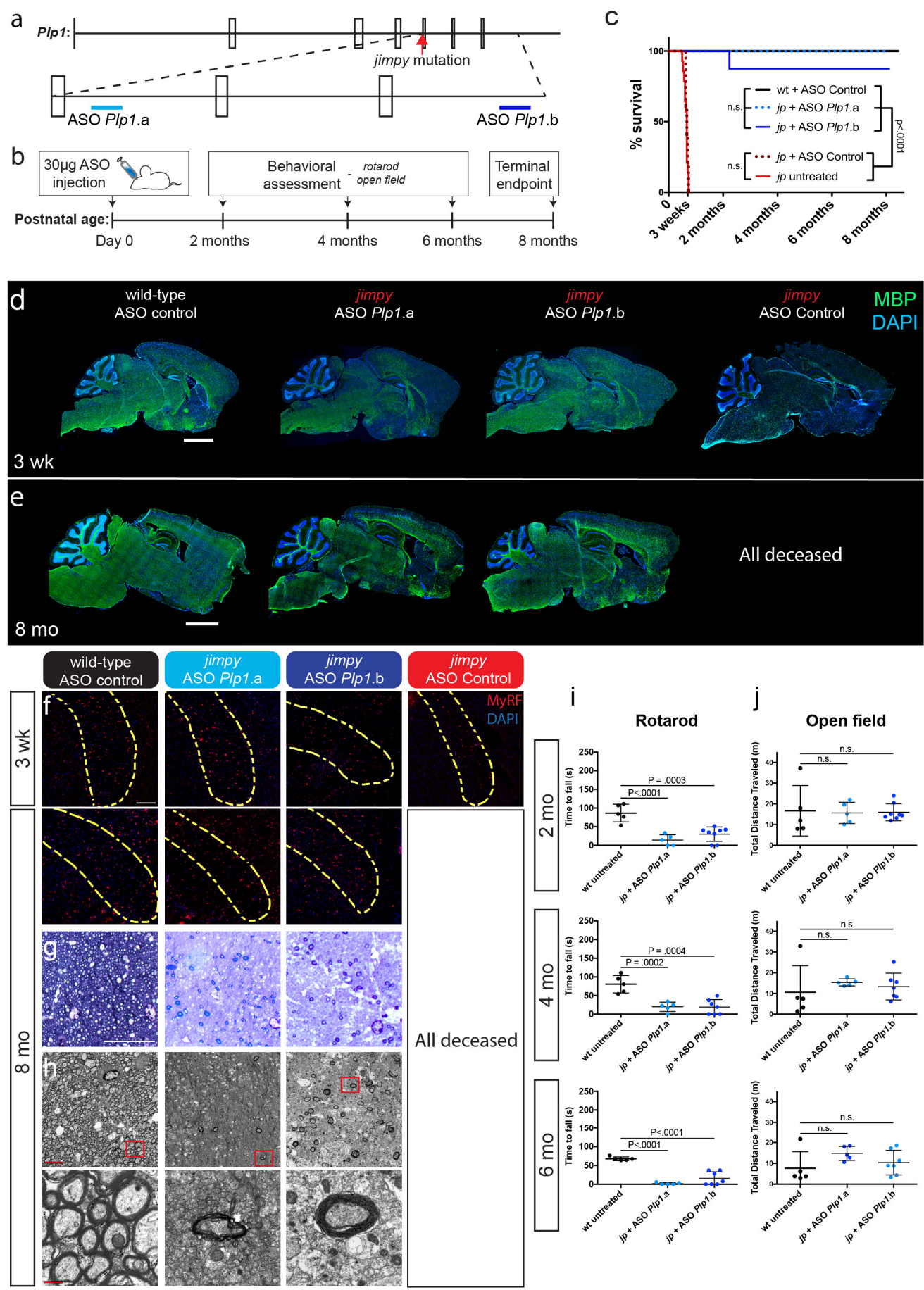

Fig. 4 | Postnatal delivery of Plp1-targeted antisense oligonucleotides rescues lifespan and partially restores functional myelinating oligodendrocytes in jimpy mice.

a, Schematic of the binding location of the two independent ASOs within intron 5 and the 3' UTR of the Plp1 pre-mRNA. The location of the jimpy mutation in the 3' splice acceptor site of intron 4 is indicated by a red arrow. 
b, Schematic of the experimental design for ASO experiments. A single 30ug dose of ASO was administered by intracerebroventricular injection into the lateral ventricle within one day after birth. Functional assessment was performed at 2, 4, and 6 months of age and the experiment was terminated for histological analyses at 8 months of age.

c, Kaplan-Meier plot depicting the survival of jimpy mice treated with two independent Plp1targeting ASOs compared to controls. Groups included: untreated wild-type $(n=5)$, wild-type treated with ASO-control $(\mathrm{n}=12)$, untreated jimpy $(\mathrm{n}=14)$, jimpy treated with ASO-control $(\mathrm{n}=5)$, jimpy treated with ASO-Plp1.a $(\mathrm{n}=5)$, and jimpy treated with ASO-Plp1.b $(\mathrm{n}=8)$. See Supplementary Fig. 3 for metadata of every animal in this study including behavioral studies at pre-determined time points. p-values calculated using the log-rank test.

d-e, Representative immunohistochemical images of 3 week (d) and 8 month (e) whole-brain sagittal sections showing MBP+ oligodendrocytes (green) and total DAPI+ cells (blue) in control and jimpy mice treated with indicated ASOs. Scale bar, $2 \mathrm{~mm}$.

f, Representative sagittal images of the 3 week old rostral corpus callosum showing MyRF+ oligodendrocytes in control and jimpy mice treated with indicated ASOs. Scale bar, 100um.

g, Representative toluidine blue stained images showing myelinated axons in the corpus callosum of 8 month old wild-type and jimpy mice treated with the indicated ASOs. Scale bar, 20um.

$\mathbf{h}$, Representative electron micrograph images showing myelination in the corpus callosum of 8 month old wild-type and jimpy animals treated with the indicated ASOs. Lower panel is a higher magnification of red boxed area in the corresponding image in the upper panel. Upper panel scale bar, 5um and lower panel scale bar is $0.5 \mathrm{um}$.

i, Comparison of motor function and coordination of 2 month $(\mathrm{n}=5,5$, and 8 for untreated wildtype, ASO-Plp1.a-treated jimpy, and ASO-Plp1.b-treated jimpy mice), 4 month $(\mathrm{n}=5,5$, and 7 for untreated wild-type, ASO-Plp1.a-treated jimpy, and ASO-Plpl.b-treated jimpy mice), and 6 month $(\mathrm{n}=5,5$, and 7 for untreated wild-type, ASO-Plp1.a-treated jimpy, and ASO-Plp1.b-treated jimpy mice) old mice by accelerating rotarod performance. Individual data points represent the mean time to fall of three separate trials for each biological replicate (separate mice). Error bars show mean \pm standard deviation. $p$-values calculated using one-way ANOVA with Dunnett's correction for multiple comparisons. See Supplementary Fig. 3 for raw data values.

j, Comparison of locomotor activity of 2 month $(n=5,5$, and 8 for untreated wild-type, ASOPlp1.a-treated jimpy, and ASO-Plp1.b-treated jimpy mice), 4 month ( $\mathrm{n}=5,5$, and 7 for untreated wild-type, ASO-Plp1.a-treated jimpy, and ASO-Plp1.b-treated jimpy mice), and 6 month (n=5, 5, and 7 for untreated wild-type, ASO-Plp1.a-treated jimpy, and ASO-Plp1.b-treated jimpy mice) old mice by open field testing. Individual data points represent total distance traveled for each biological replicate (separate mice). Error bars show mean \pm standard deviation. p-values calculated using one-way ANOVA with Dunnett's correction for multiple comparisons. See Supplementary Fig. 3 for raw data values. 


\begin{tabular}{|c|c|c|c|}
\hline Mouse & Genotype & Indel & Off-target DSB \\
\hline 1 & Wild-type & $\begin{array}{l}\text { In-frame shift from dual cutting }(29 \%) \\
\text { Frameshift from sgRNA } 7(71 \%)\end{array}$ & None \\
\hline 2 & Wild-type & $\begin{array}{c}\text { Frameshift from dual cutting (61\%) } \\
\text { Frameshift from sgRNA } 7(39 \%)\end{array}$ & None \\
\hline 3 & Wild-type & Frameshift from sgRNA $7(100 \%)$ & $48 \%$ (sgRNA 7 ) \\
\hline 4 & jimpy & Frameshift from dual cutting (100\%) & $48 \%$ (sgRNA 7$)$ \\
\hline 5 & Wild-type & Frameshift from dual cutting (100\%) & $51 \%$ (sgRNA 7 ) \\
\hline 6 & Wild-type & Frameshift from sgRNA $7(100 \%)$ & None \\
\hline 7 & Wild-type & Frameshift from sgRNA $7(26 \%)$ & None \\
\hline
\end{tabular}

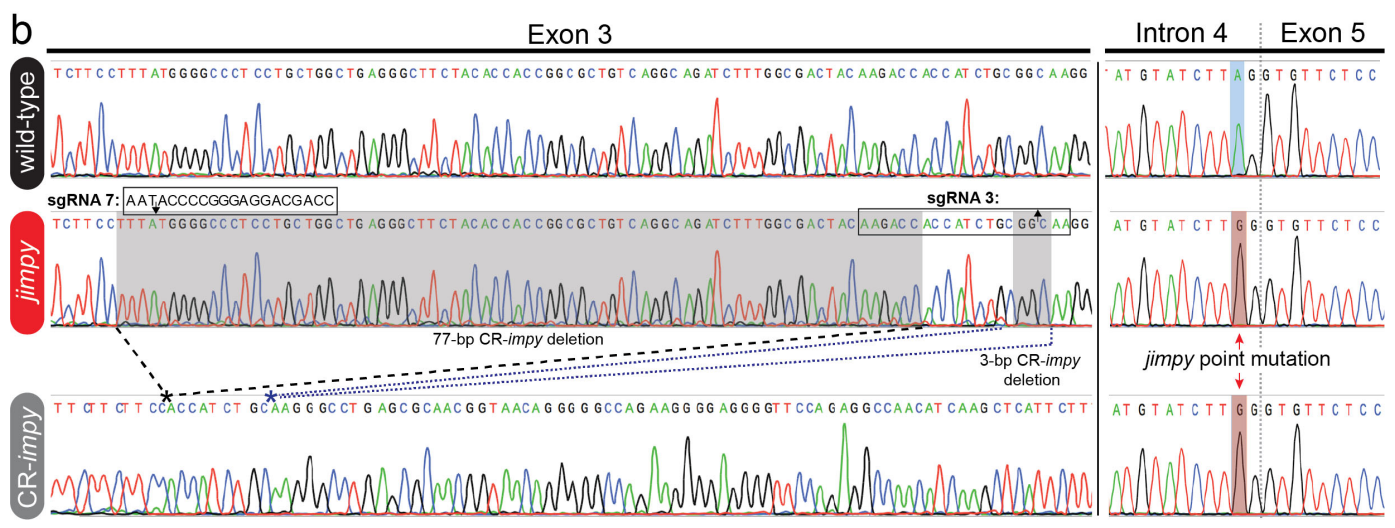

C

PIp1 expression (RNA)
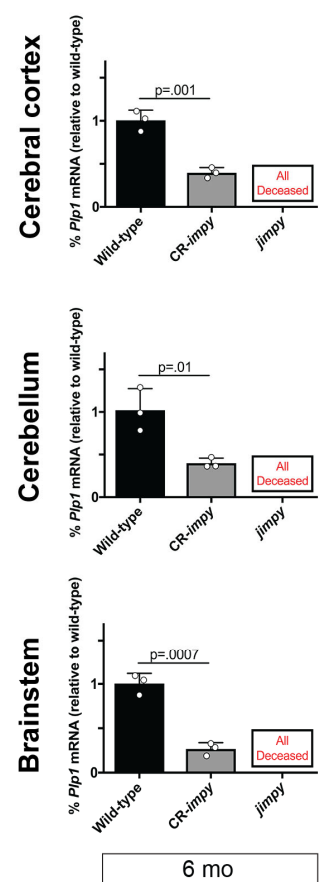

d
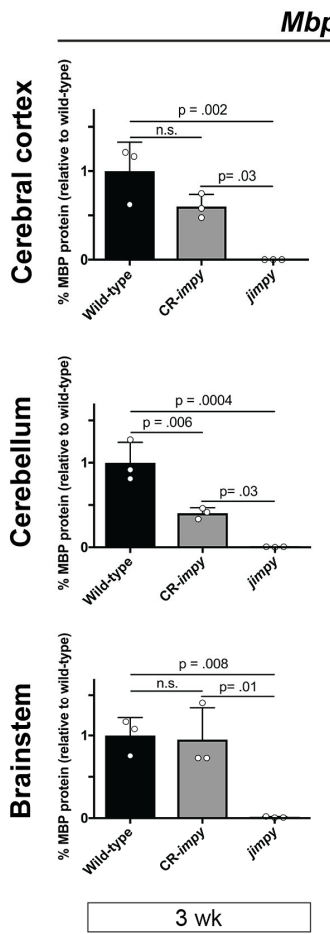

e bp expression (RNA and protein) transcript and protein levels.
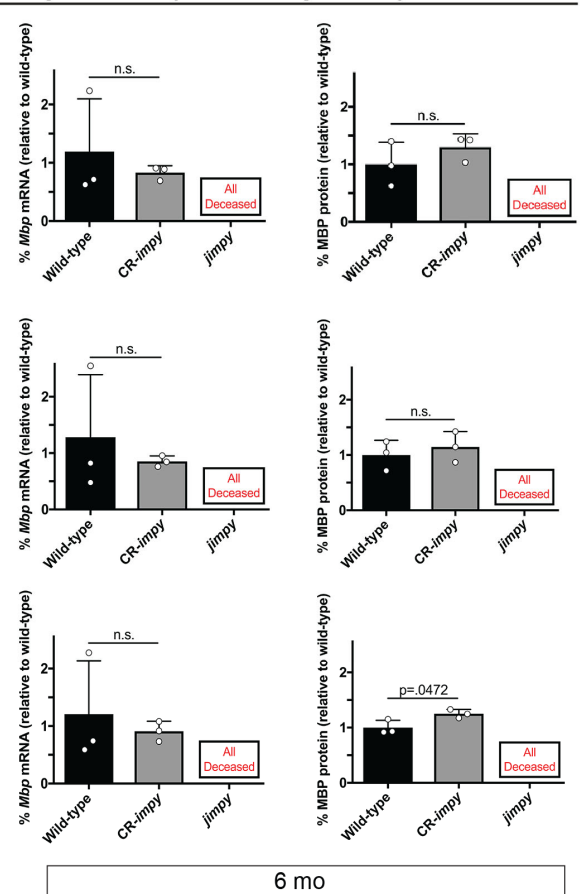

Extended Data Fig. 1 | CRISPR-mediated knockdown of Plp1 in jimpy mice increases MBP

a, Table showing the on- and off-target mutations for sgRNAs 3 and 7 after electroporation into mouse zygotes and measured by high-throughput sequencing of tail tip DNA from founder 
animals. Mouse number 4, a jimpy male with a complex, frameshift deletion including 80-bp of total deleted sequence in Plp1 exon 3, served as the founder for the CR-impy cohort.

b, Annotated Sanger sequencing traces of wild-type, jimpy, and CR-impy mice showing the complex, frameshift in Plpl exon 3 from dual cutting of CRISPR/spCas 9 sgRNAs in CR-impy mice as well as the jimpy point mutation in intron 4. sgRNA 3 and 7 sequences outlined by black boxes with the predicted double strand break site shown a black arrow.

c, RT-qPCR data comparing the level of Plp1 transcript in 6 month old CR-impy mice relative to wild-type mice in three different brain regions (cerebral cortex, cerebellum, and brainstem). Primer sites span Plpl exons 2-3, upstream of CR-impy complex, frameshift deletion and jimpy mutation sites. Individual data points represent the mean value of 4 technical replicates for each biological replicate ( $\mathrm{n}=3$ separate mice). Error bars show mean \pm standard deviation. $\mathrm{p}$-values calculated using a two-way, unpaired t-test.

d, Western blot data comparing the level MBP in 3 week old CR-impy and jimpy mice relative to wild-type mice across three different brain regions (cerebral cortex, cerebellum, and brainstem). $\mathrm{n}=3$ biological replicates (separate mice) per genotype (see Supplementary Fig. 2 for full western blot images for all samples). Error bars show mean \pm standard deviation. p-values calculated using a one-way ANOVA with Tukey correction for multiple comparisons.

e, RT-qPCR data comparing the level of $M b p$ transcript in 6 month old CR-impy mice relative to wild-type mice in three different brain regions (cerebral cortex, cerebellum, and brainstem). Individual data points represent the mean value of 4 technical replicates for each biological replicate ( $\mathrm{n}=3$ separate mice). Error bars show mean \pm standard deviation. $p$-values calculated using a two-way, unpaired t-test.

f, Western blot data comparing the level MBP in 6 month old CR-impy mice relative to wild-type mice in three different brain regions (cerebral cortex, cerebellum, and brainstem). $n=3$ biological replicates (separate mice) per genotype (see Supplementary Fig. 2 for full western blot images for all samples). Error bars show mean \pm standard deviation. p-values calculated using a two-way, unpaired t-test. 

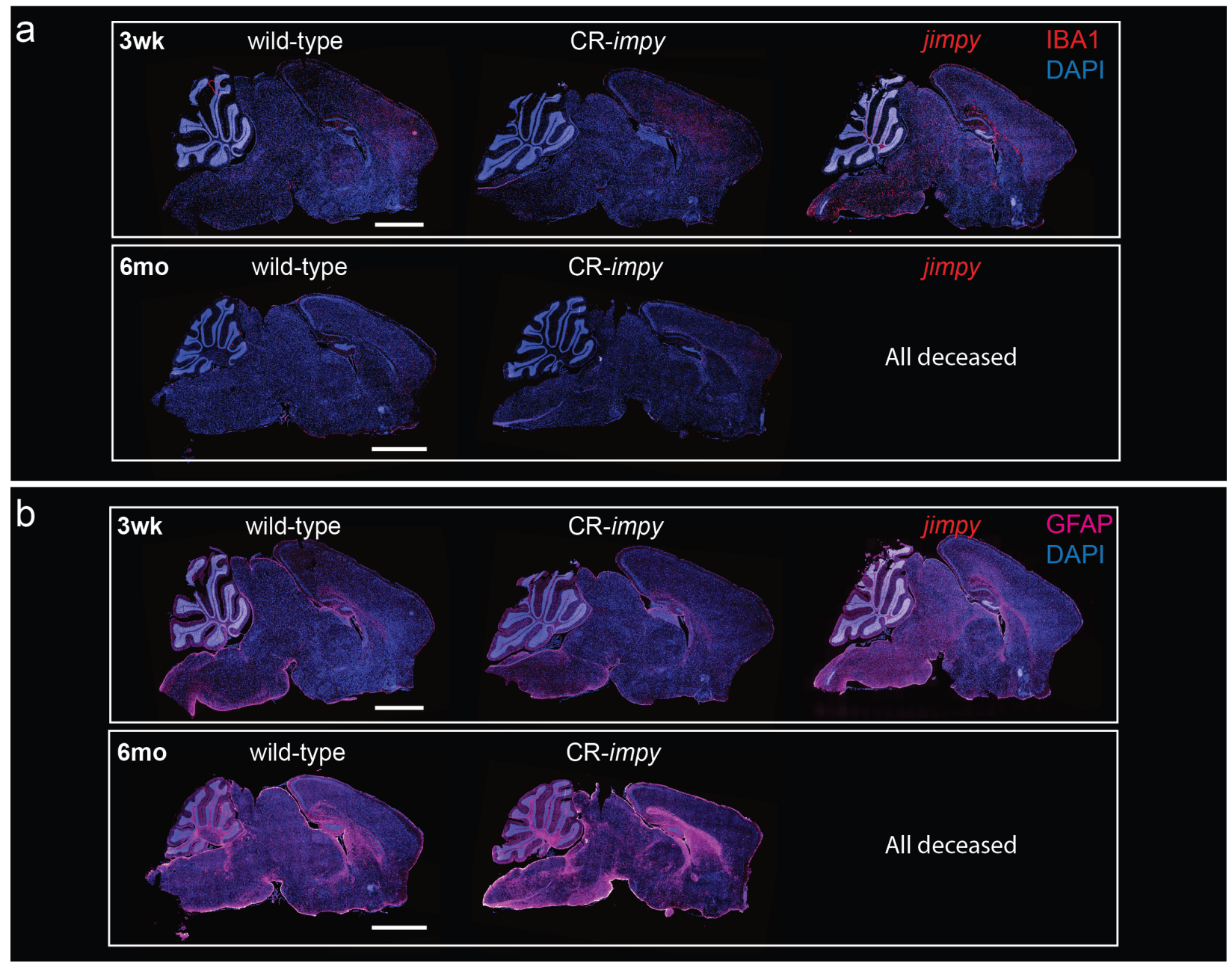

Extended Data Fig. 2 | CRISPR-mediated knockdown of Plp1 in jimpy mice reduces activated microglia and astrocyte markers.

a, Representative immunohistochemical images of whole-brain sagittal sections showing IBA1+ activated microglia (red), and total DAPI+ cells (blue) in wild-type, CR-impy, and jimpy mice at 3 weeks and 6 months of age as indicated. Scale bar, $2 \mathrm{~mm}$. astrocytes (magenta), and total DAPI+ cells (blue) in wild-type, CR-impy, and jimpy mice at 3 weeks and 6 months of age as indicated. Scale bar, $2 \mathrm{~mm}$. 

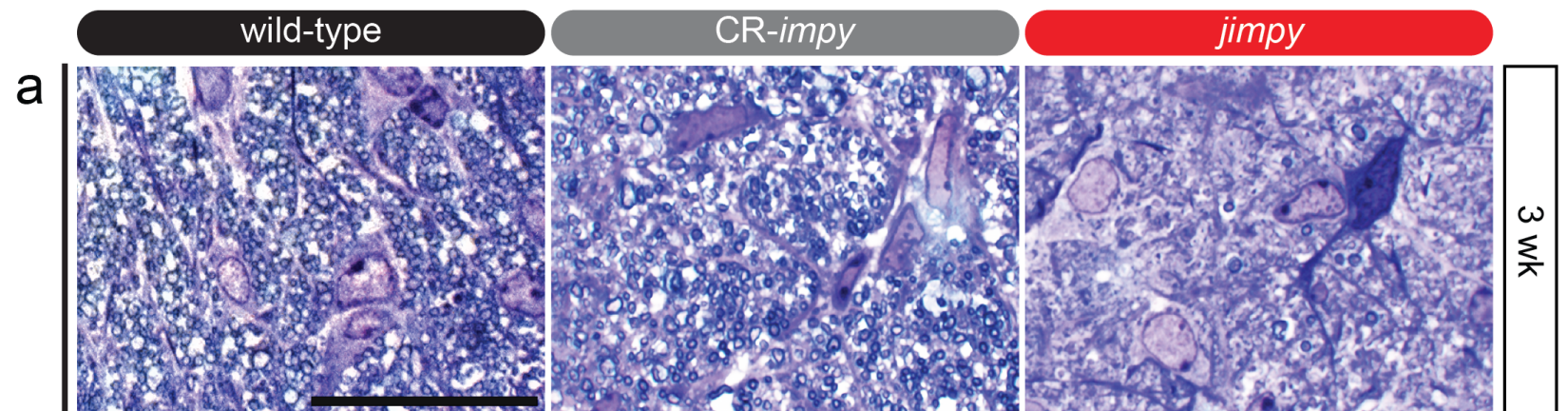

b
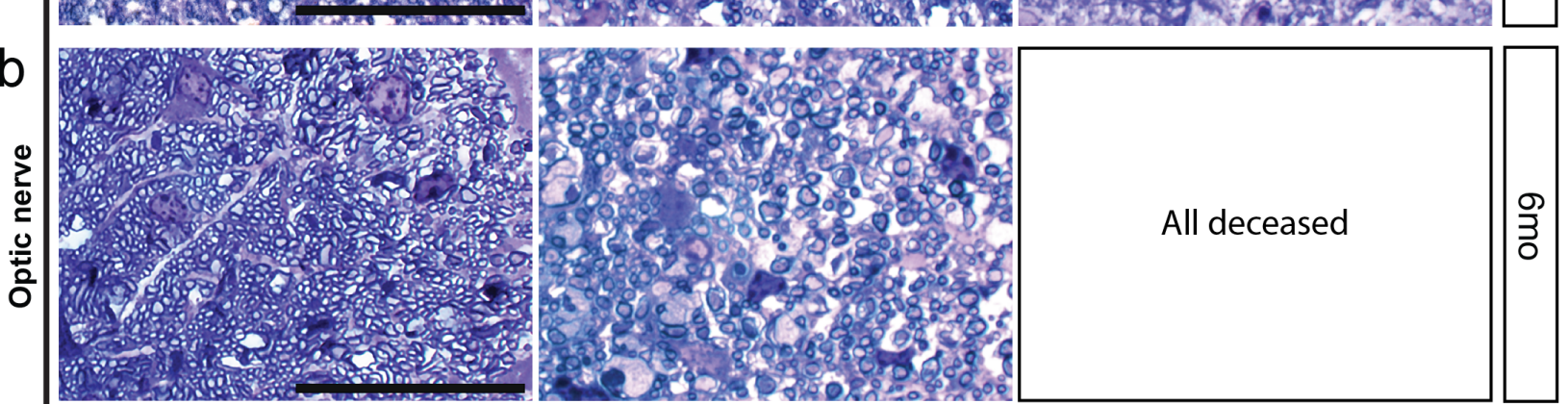

C
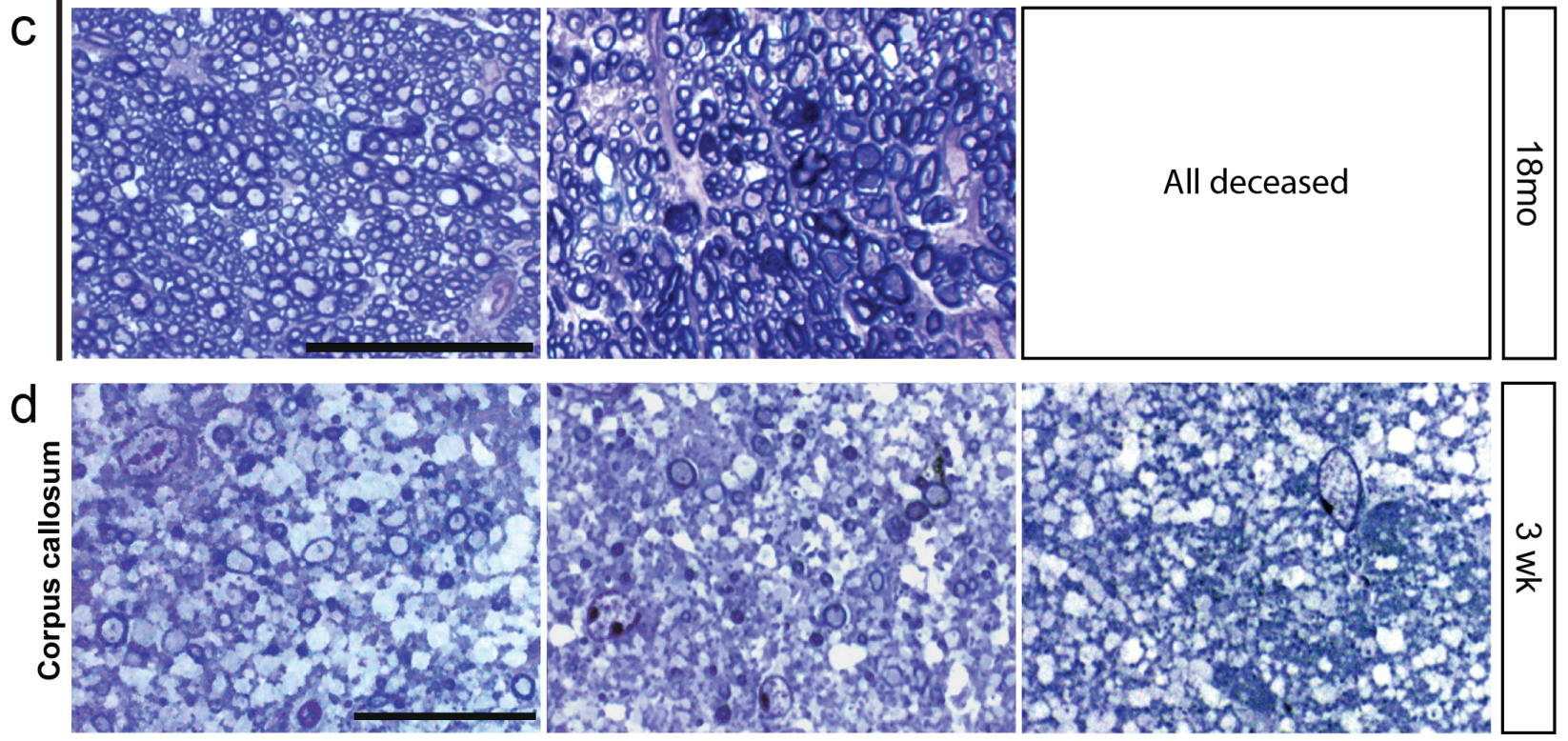

912

\section{Extended Data Fig. 3 | CRISPR-mediated knockdown of Plp1 in jimpy mice increases myelination.}

a, Representative images of toluidine blue-stained optic nerve sections from 3 week old wild-type, CR-impy, and jimpy mice. Scale bar, $20 \mu \mathrm{m}$.

b-c, Representative images of toluidine blue-stained optic nerve sections from 6 month (b) and 18 month (c) old wild-type, CR-impy, and jimpy mice. Scale bar, $20 \mu \mathrm{m}$.

d, Representative images of toluidine blue-stained corpus callosum sections from 3 week old wildtype, CR-impy, and jimpy mice. Scale bar, $20 \mu \mathrm{m}$. 
a

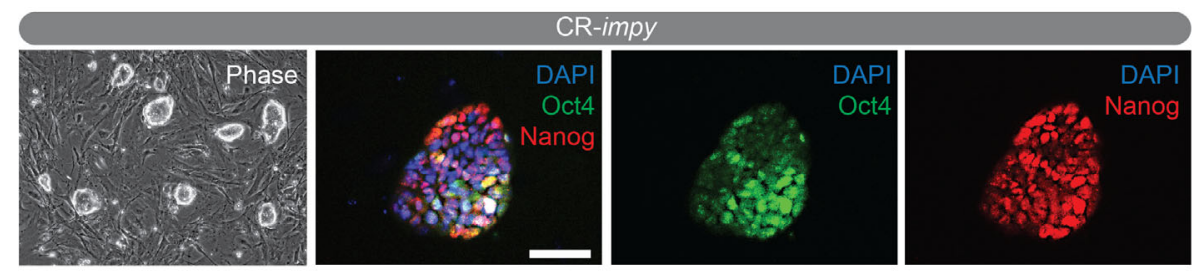

b
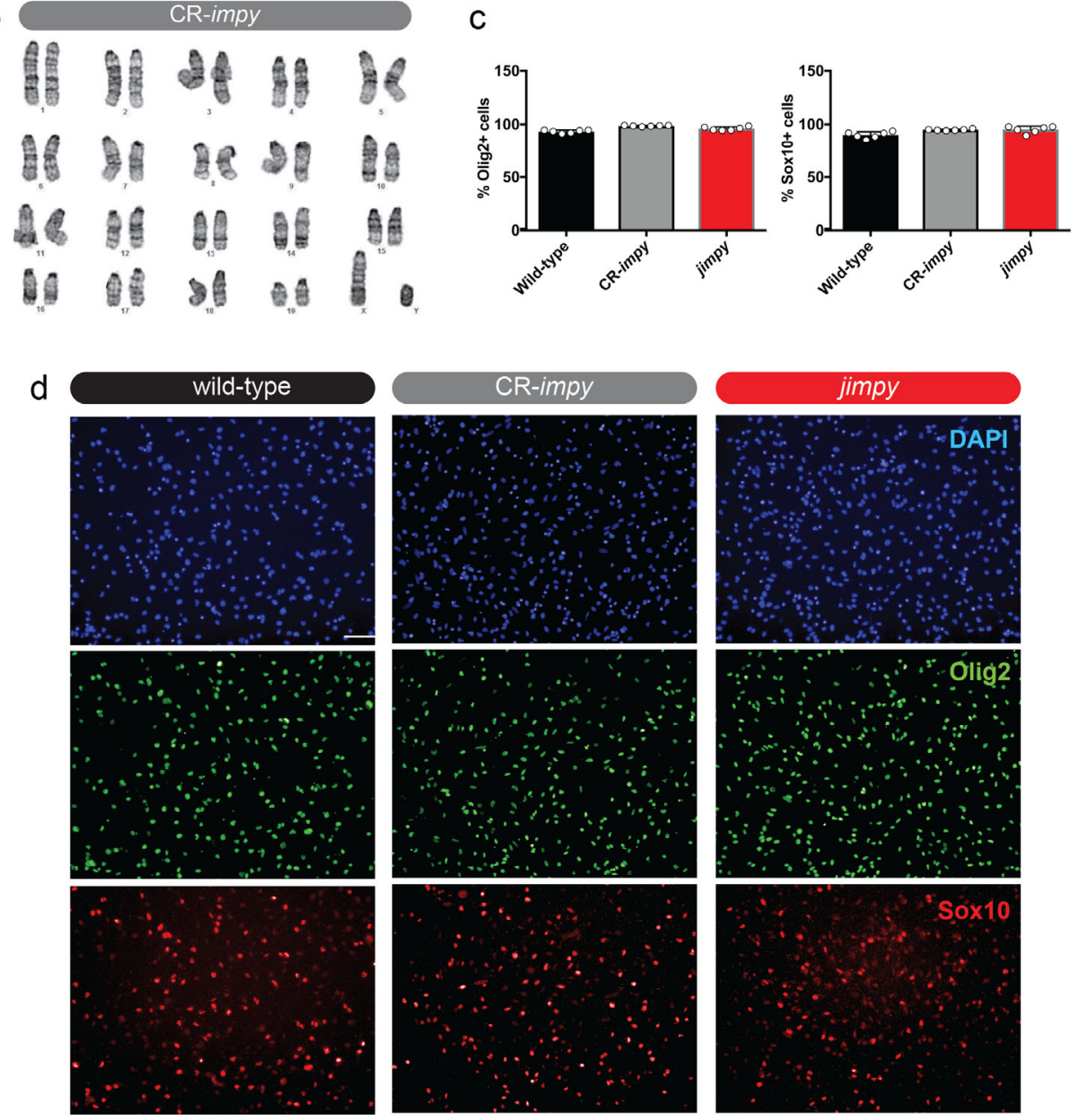

\section{Extended Data Fig. 4 | Characterization of mouse iPSC lines and derivation of OPCs.}

a, Representative phase and immunocytochemistry images of Oct4+ (green) and Nanog+ (red) iPSCs reprogrammed from CR-impy, tail-tip fibroblasts. Scale bar, 50um.

b, Normal karyotype of CR-impy iPSC line used to generate OPCs.

c, Percentage of Sox10+ and Olig2+ cells in OPCs cultures from wild-type, CR-impy, and jimpy iPSCs. Error bars show mean \pm standard deviation. $n=6$ technical replicates (single cell line per genotype with 6 separate wells scored).

d, Representative immunocytochemistry images showing relative purity of Olig2+ and Sox10+ OPCs derived from wild-type, CR-impy, and jimpy iPSCs. Scale bar, 100um. 

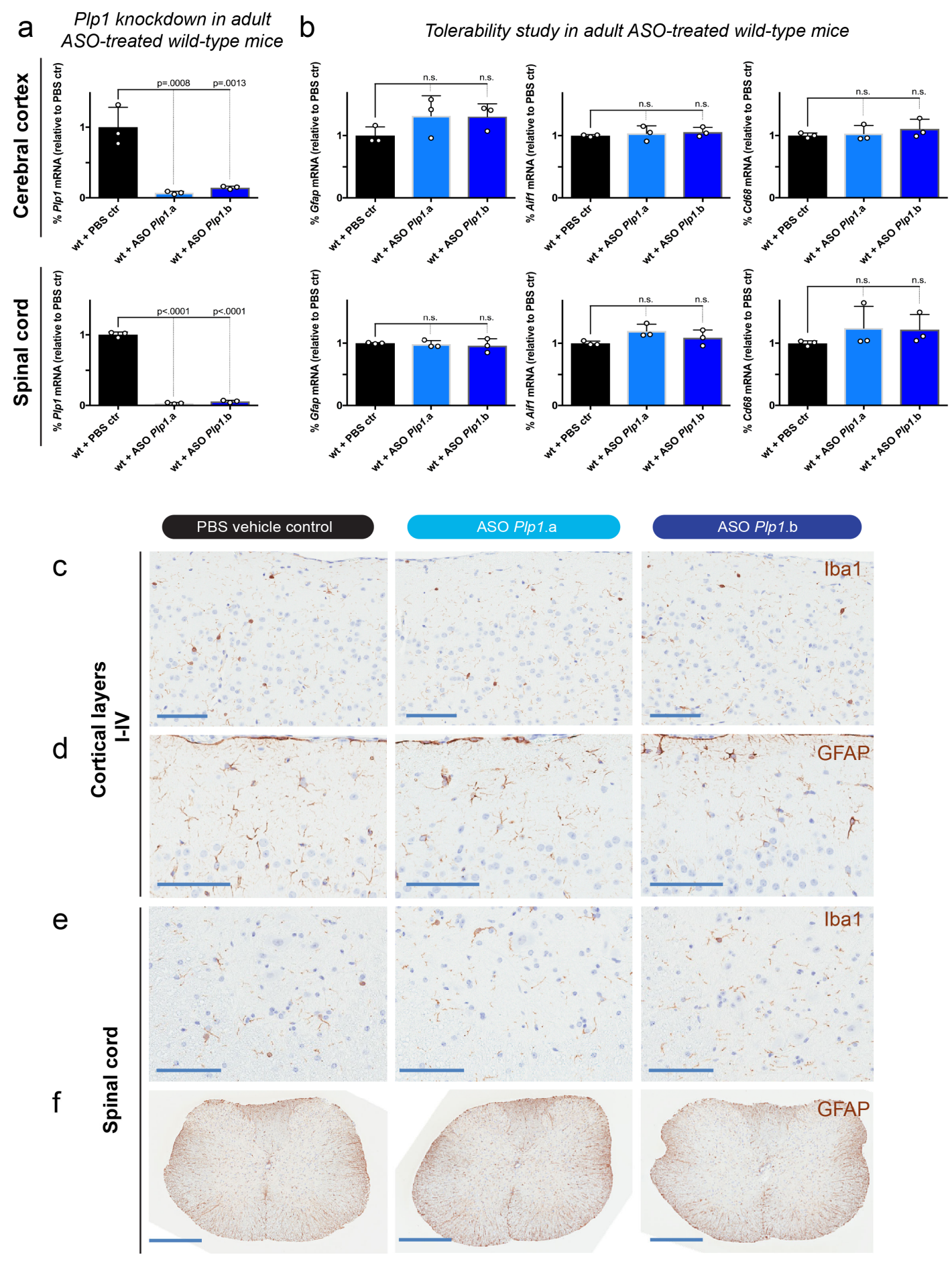

Extended Data Fig. 5 | Plp1-targeted ASOs show robust and sustained Plp1 suppression and do not alter markers of glial activation/recruitment in wild-type adult mouse CNS.

a, RT-qPCR data comparing the level of Plpl transcript suppression in 16 week old cerebral cortex and spinal cord of wild-type mice treated with the indicated ASOs (300ug dose) or controls at 
week 8. Individual data points represent the mean value of 3 technical replicates for each biological replicate ( $\mathrm{n}=3$ separate mice). Error bars show mean \pm standard deviation. $\mathrm{p}$-values calculated using one-way ANOVA with Dunnett's correction for multiple comparisons. b, RT-qPCR data assessing ASO tolerability by expression levels of Gfap (astrocyte marker), Aif1 (microglia marker), and Cd68 (monocyte/macrophage marker) transcripts in 16 week old cerebral cortex and spinal cord of wild-type mice treated with the indicated ASOs (300ug dose) or controls at week 8. Individual data points represent the mean value of 3 technical replicates for each biological replicate ( $\mathrm{n}=3$ separate mice). Error bars show mean \pm standard deviation. $\mathrm{p}$-values calculated using one-way ANOVA with Dunnett's correction for multiple comparisons.

c-f, Ibal or GFAP immunohistochemistry (brown) with hematoxylin counterstain (purple) showing no appreciable increase among groups in staining intensity, cellularity, or shortened, thick processes that would be consistent with glial activation. (c) cortical layers I-IV Iba1 staining, scale bar $=100 \mu \mathrm{m}$ (d) cortical layers I-III GFAP staining, scale bar $=100 \mu \mathrm{m}$. (e) spinal cord dorsal horn grey/white matter intersection Ibal staining, scale bar $=100 \mu \mathrm{m}$. (f) Spinal cord GFAP staining, scale bar $=500 \mu \mathrm{m}$. 

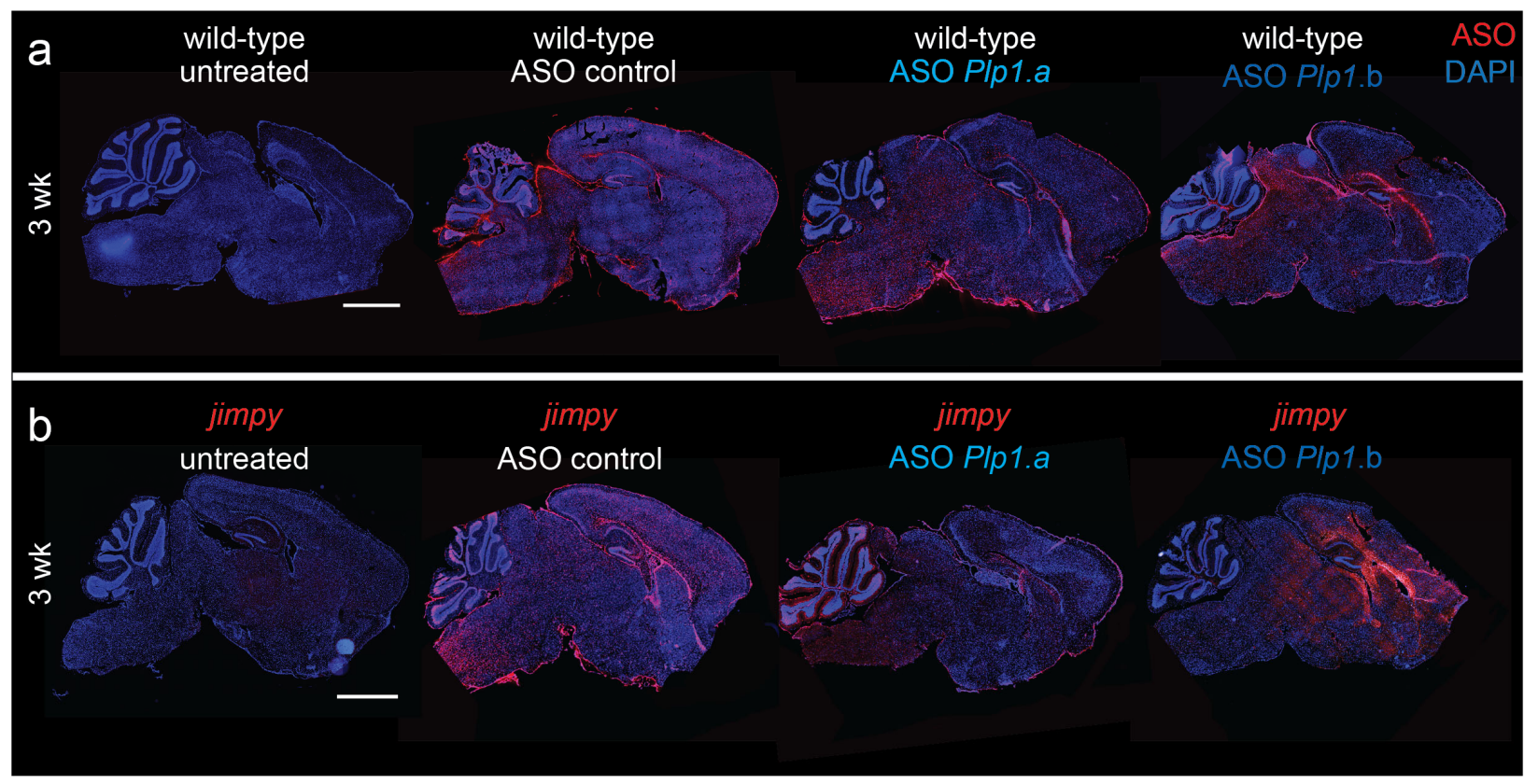

Extended Data Fig. 6 | Plp1-targeted ASOs distribute widely throughout the CNS after ICV dosing in postnatal mice. ASO (red) and total DAPI+ cells (blue) in wild-type mice (a) or jimpy (b) mice treated with ASOPlp1.a, ASO-Plp1.b, or a control ASO by ICV injection at birth. Scale bar, $2 \mathrm{~mm}$. 

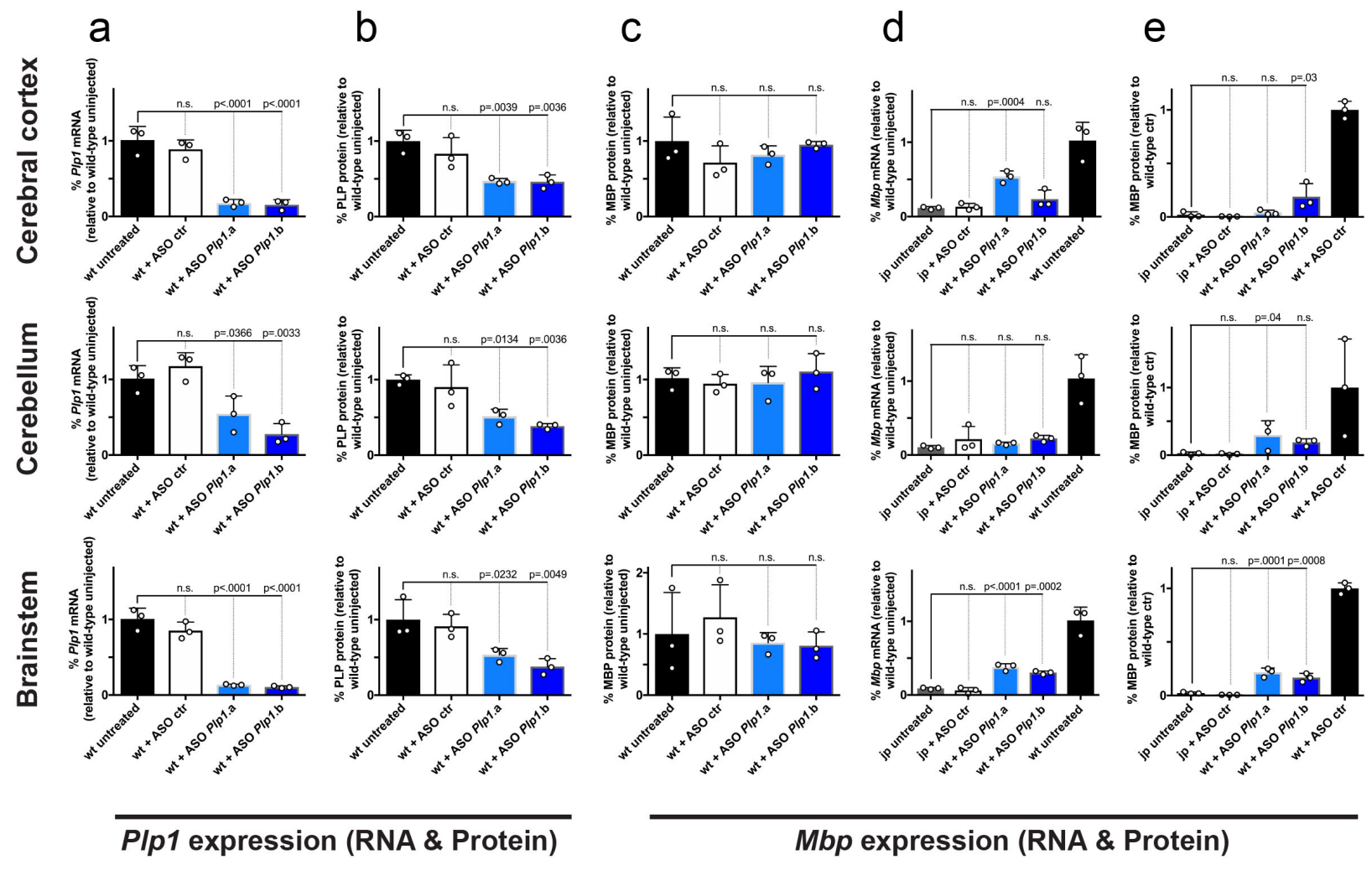

Extended Data Fig. 7 | Plp1-targeted ASOs increase MBP transcript and protein levels in jimpy mice.

a, RT-qPCR data showing the level of Plpl transcript suppression in 3 week old cerebral cortex, cerebellum, and brainstem of wild-type mice treated with the indicated ASOs (30ug dose) or controls at birth. Primer sites span Plpl exons 2-3, upstream of the jimpy mutation site. Individual data points represent the mean value of 4 technical replicates for each biological replicate $(n=3$ separate mice). Error bars show mean \pm standard deviation. p-values calculated using one-way ANOVA with Dunnett's correction for multiple comparisons.

b, Western blot data showing the levels of PLP in 3 week old cerebral cortex, cerebellum, and brainstem of wild-type mice treated with the indicated ASOs (30ug dose) or controls at birth. Individual data points represent biological replicates $(n=3$ separate mice; see Supplementary Fig. 4 for full western blot images for all samples). Error bars show mean \pm standard deviation. $\mathrm{p}$ values calculated using one-way ANOVA with Dunnett's correction for multiple comparisons. c, Western blot data showing the levels of MBP in 3 week old cerebral cortex, cerebellum, and brainstem of wild-type mice treated with the indicated ASOs (30ug dose) or controls at birth. Individual data points represent biological replicates $(n=3$ separate mice; see Supplementary Fig. 4 for full western blot images for all samples). Error bars show mean \pm standard deviation. $\mathrm{p}$ values calculated using one-way ANOVA with Dunnett's correction for multiple comparisons. 
Individual data points represent the mean value of 4 technical replicates for each biological replicate ( $\mathrm{n}=3$ separate mice). Error bars show mean \pm standard deviation. $\mathrm{p}$-values calculated using one-way ANOVA with Dunnett's correction for multiple comparisons.

e, Western blot data showing the level of MBP in 3 week old cerebral cortex, cerebellum, and brainstem of jimpy mice treated with the indicated ASOs (30ug dose) or controls at birth. Individual data points represent biological replicates ( $n=3$ separate mice; see Supplementary Fig. 4 for full western blot images for all samples). Error bars show mean \pm standard deviation. $p$ values calculated using one-way ANOVA with Dunnett's correction for multiple comparisons. 
EXTENDED DATA TABLE 1

\begin{tabular}{|c|c|c|c|c|c|}
\hline PLP1 mutation & Patient \# & Motor function & Cognitive function & Death & Ref. \\
\hline \multirow{4}{*}{$\begin{array}{l}\text { Frameshift and } \\
\text { early termination } \\
\text { codon } \\
\text { (c.4delG) } \\
\text { Protein absence } \\
\text { confirmed by } \\
\text { western blot }\end{array}$} & 1 & $\begin{array}{l}\text { Wheelchair bound } \\
\text { at } 35 \text { with spasticity } \\
\text { in all limbs }\end{array}$ & $\begin{array}{l}\text { No intellectual disability } \\
\text { and verbally communicated } \\
\text { into mid-20s. Cooperative, } \\
\text { alert, and aware of } \\
\text { surroundings in adulthood. }\end{array}$ & Age 47 & $(1,2)$ \\
\hline & 2 & $\begin{array}{l}\text { Wheelchair bound } \\
\text { at } 37 \text { with spasticity } \\
\text { in all limbs }\end{array}$ & $\begin{array}{l}\text { No intellectual disability and } \\
\text { verbally communicated into } \\
\text { mid-20s. Cooperative, alert, } \\
\text { and aware of surroundings in } \\
\text { adulthood. }\end{array}$ & Age 49 & \\
\hline & 3 & $\begin{array}{l}\text { Walked from age 4- } \\
12, \text { spasticity in all } \\
\text { limbs at age } 25\end{array}$ & $\begin{array}{l}\text { Language delay. At } 22 \\
\text { communicated, was } \\
\text { cooperative, and alert. At } 25 \\
\text { could follow commands, } \\
\text { count, and distinguish colors. }\end{array}$ & Age 34 & \\
\hline & 4 & $\begin{array}{l}\text { Wheelchair bound } \\
\text { at } 17, \text { gait } \\
\text { deterioration } \\
\text { starting at age } 8 \text {, } \\
\text { and spasticity in } \\
\text { legs but not arms. }\end{array}$ & $\begin{array}{l}\text { Able to read, follow } \\
\text { commands, and perform } \\
\text { arithmetic. }\end{array}$ & $\begin{array}{l}\text { None } \\
\text { reported }\end{array}$ & \\
\hline $\begin{array}{l}\text { Frameshift and } \\
\text { early termination } \\
\text { codon } \\
\text { c. } 191+1 G>A \\
\text { No biochemical } \\
\text { analysis }\end{array}$ & 1 & $\begin{array}{l}\text { Walked from age 6- } \\
\text { 9. Spastic with } \\
\text { cerebellar } \\
\text { dysfunction. }\end{array}$ & $\begin{array}{l}\text { Attends normal school and } \\
\text { can read and write. }\end{array}$ & $\begin{array}{l}\text { None } \\
\text { reported }\end{array}$ & (3) \\
\hline \multirow{3}{*}{$\begin{array}{l}\text { Loss of start } \\
\text { codon } \\
\text { (c.3G>A) } \\
\text { No biochemical } \\
\text { analysis }\end{array}$} & 1 & $\begin{array}{l}\text { Early life motor } \\
\text { dysfunction with } \\
\text { spasticity in arms } \\
\text { and legs. Further } \\
\text { decline at age } 33 .\end{array}$ & $\begin{array}{l}\text { Early life intellectual disability. } \\
\text { Further decline at age } 33 \text {. }\end{array}$ & $\begin{array}{l}\text { None } \\
\text { reported }\end{array}$ & $(2,4)$ \\
\hline & 2 & $\begin{array}{l}\text { Early life hypertonia } \\
\text { and spasticity in } \\
\text { arms and legs. } \\
\text { Wheelchair bound } \\
\text { at } 6 .\end{array}$ & $\begin{array}{l}\text { Language delay. Moderately } \\
\text { retarded development. }\end{array}$ & $\begin{array}{l}\text { None } \\
\text { reported }\end{array}$ & \\
\hline & 3 & $\begin{array}{l}\text { Never walked and } \\
\text { spasticity in legs by } \\
\text { age } 1 \text {, progressing } \\
\text { to arms with age. }\end{array}$ & $\begin{array}{l}\text { Mild cognitive deficits at age } \\
20 .\end{array}$ & $\begin{array}{l}\text { None } \\
\text { reported }\end{array}$ & (5) \\
\hline
\end{tabular}

\section{Extended Data Table 1}

Table containing details of published reports of $P L P 1$-null patients. 
bioRxiv preprint doi: https://doi.org/10.1101/508192; this version posted December 31, 2018. The copyright holder for this preprint (which was not certified by peer review) is the author/funder, who has granted bioRxiv a license to display the preprint in perpetuity. It is made available under aCC-BY-NC-ND 4.0 International license.

SUPPLEMENTARY FIGURE 1

1004

\begin{tabular}{|c|c|c|c|c|c|c|c|c|c|c|c|c|c|c|c|c|}
\hline \multicolumn{9}{|c|}{ Metadata for monse CRISPR survival cohort from Elitt et al. ver.12-25-18 } & \multicolumn{4}{|c|}{ mean time to fall (seconds) } & \multicolumn{4}{|c|}{ total distance traveled (meters) } \\
\hline Identifier & Date of birth & Date of death & $\begin{array}{l}\text { Euthanized at } \\
18 \text { month } \\
\text { endpoint? }\end{array}$ & Lifespan (days) & Genotype & Phenotype & Censored (Y/N) & Censor Reason & $\begin{array}{c}\text { Rotarod } \\
3 \mathrm{wk}\end{array}$ & $\begin{array}{c}\text { Rotarod } \\
2 \mathrm{mo}\end{array}$ & $\begin{array}{c}\text { Rotarod } \\
6 \mathrm{mo}\end{array}$ & $\begin{array}{c}\text { Rotarod } \\
18 \mathrm{mo} \\
\end{array}$ & $\begin{array}{c}\text { Open field } \\
3 \text { wk }\end{array}$ & $\begin{array}{c}\text { Open field } \\
2 \text { mo }\end{array}$ & $\begin{array}{c}\text { Open field } \\
6 \mathrm{mo}\end{array}$ & $\begin{array}{c}\text { Open field } \\
18 \mathrm{mo}\end{array}$ \\
\hline CR200301 & $11 / 13 / 2016$ & $4 / 22 / 2018$ & $\mathrm{n}$ & 525 & wild-type & none & $\mathrm{N}$ & & 69.3 & 70.9 & 61.8 & & 22.8 & 17.9 & 12.5 & \\
\hline CR200090 & $11 / 13 / 2016$ & $5 / 14 / 2018$ & $\mathrm{y}$ & 547 & wild-type & none & $\mathrm{N}$ & & 144.0 & 104.1 & 60.1 & 43.0 & 17.0 & 17.4 & 10.8 & 13.2 \\
\hline CR200091 & $11 / 13 / 2016$ & $5 / 14 / 2018$ & $\mathrm{y}$ & 547 & wild-type & none & $\mathrm{N}$ & & 81.3 & 103.4 & 77.5 & 61.3 & 19.3 & 18.8 & 10.2 & 15.4 \\
\hline CR200302 & $11 / 15 / 2016$ & $12 / 5 / 2017$ & $\mathrm{n}$ & 385 & CR-impy & none & $\mathrm{N}$ & & 100.7 & 120.9 & 108.0 & & 10.9 & 15.0 & 15.5 & \\
\hline CR200303 & $11 / 15 / 2016$ & $12 / 28 / 2017$ & $\mathrm{n}$ & 408 & CR-impy & none & $\mathrm{N}$ & & 115.3 & 138.0 & 74.2 & & 8.6 & 14.3 & 17.7 & \\
\hline $\begin{array}{l}\text { CR200304 } \\
\end{array}$ & $11 / 15 / 2016$ & $5 / 6 / 2018$ & $\mathrm{n}$ & 537 & CR-impy & none & $\mathrm{N}$ & & 95.7 & 138.3 & 55.2 & & 13.7 & 11.0 & 11.5 & \\
\hline CR200092 & $11 / 15 / 2016$ & $5 / 14 / 2018$ & $\mathrm{y}$ & 545 & CR-impy & none & $\mathrm{N}$ & & 139.4 & 106.3 & 66.2 & 16.3 & 10.1 & 10.2 & 10.5 & 7.3 \\
\hline $\begin{array}{l}\text { CR200093 } \\
\end{array}$ & $11 / 15 / 2016$ & $5 / 14 / 2018$ & $\mathrm{y}$ & 545 & CR-impy & none & $\mathrm{N}$ & & 72.7 & 117.7 & 116.3 & 29.2 & 17.1 & 7.9 & 17.3 & 22.0 \\
\hline CR200305 & $11 / 15 / 2016$ & $12 / 8 / 2016$ & $n$ & 23 & jimpy & severe & $\mathrm{N}$ & & 39.1 & & & & 3.9 & & & \\
\hline CR200306 & $11 / 15 / 2016$ & $12 / 7 / 2016$ & $\mathrm{n}$ & 22 & jimpy & severe & $\mathrm{N}$ & & 21.0 & & & & 2.4 & & & \\
\hline CR200307 & $11 / 15 / 2016$ & $12 / 9 / 2016$ & $\mathrm{n}$ & 24 & jimpy & severe & $\mathrm{N}$ & & 20.7 & & & & 1.0 & & & \\
\hline CR200308 & $11 / 15 / 2016$ & $12 / 5 / 2016$ & $\mathrm{n}$ & 20 & jimpy & severe & $\mathrm{N}$ & & 12.9 & & & & 5.5 & & & \\
\hline $\begin{array}{l}\text { CR200309 } \\
\end{array}$ & $11 / 15 / 2016$ & $\begin{array}{ll}12 / 6 / 2016 \\
\end{array}$ & $\mathrm{n}$ & 21 & jimpy & severe & $\mathrm{N}$ & & 4.7 & & & & 6.8 & & & \\
\hline CR200310 & $11 / 16 / 2016$ & $12 / 17 / 2016$ & $n$ & 31 & jimpy & severe & $\mathrm{N}$ & & 38.7 & & & & 0.4 & & & \\
\hline CR200311 & $11 / 16 / 2016$ & $12 / 10 / 2016$ & $\mathrm{n}$ & 24 & jimpy & severe & $\mathrm{N}$ & & 31.9 & & & & 0.6 & & & \\
\hline $\begin{array}{l}\text { CR200312 } \\
\end{array}$ & $11 / 17 / 2016$ & $4 / 30 / 2018$ & $\mathrm{n}$ & 529 & wild-type & none & $\mathrm{N}$ & & 101.6 & 84.7 & 52.9 & & 19.0 & 7.0 & 8.1 & \\
\hline CR200096 & $11 / 17 / 2016$ & $5 / 14 / 2018$ & $\mathrm{y}$ & 543 & wild-type & none & $\mathrm{N}$ & & 93.0 & 219.3 & 125.7 & 29.1 & 20.0 & 25.7 & 12.7 & 12.5 \\
\hline CR200313 & $11 / 17 / 2016$ & $3 / 27 / 2018$ & $\mathrm{n}$ & 495 & wild-type & none & $\mathrm{N}$ & & 156.7 & 70.4 & 52.6 & & 14.4 & 17.0 & 9.3 & \\
\hline CR200097 & $11 / 17 / 2016$ & $5 / 14 / 2018$ & $\mathrm{y}$ & 543 & wild-type & none & $\mathrm{N}$ & & 55.9 & 86.0 & 118.8 & 71.9 & 15.6 & 18.0 & 25.1 & 14.1 \\
\hline CR200094 & $11 / 18 / 2016$ & $5 / 14 / 2018$ & $\mathrm{y}$ & 542 & CR-impy & none & $\mathrm{N}$ & & 65.8 & 74.0 & 111.1 & 16.3 & 22.5 & 15.8 & 16.2 & 7.2 \\
\hline CR200314 & $11 / 18 / 2016$ & $3 / 19 / 2018$ & $\mathrm{n}$ & 486 & CR-impy & none & $\mathrm{N}$ & & 69.6 & 71.3 & 90.9 & & 21.1 & 17.0 & 15.5 & \\
\hline CR200095 & $11 / 18 / 2016$ & $5 / 14 / 2018$ & $\mathrm{y}$ & 542 & CR-impy & none & $\mathrm{N}$ & & 110.1 & 128.3 & 148.1 & 29.2 & 19.1 & 26.4 & 19.6 & 27.6 \\
\hline CR200315 & $11 / 26 / 2016$ & $12 / 22 / 2016$ & $\mathrm{n}$ & 26 & jimpy & severe & $\mathrm{N}$ & & 2.7 & & & & 1.8 & & & \\
\hline CR200316 & $11 / 26 / 2016$ & $12 / 18 / 2016$ & $\mathrm{n}$ & 22 & jimpy & severe & $\mathrm{N}$ & & 27.3 & & & & 0.5 & & & \\
\hline CR200317 & $11 / 26 / 2016$ & $12 / 18 / 2016$ & $\mathrm{n}$ & 22 & jimpy & severe & $\mathrm{N}$ & & 24.2 & & & & 0.9 & & & \\
\hline CR200318 & $11 / 26 / 2016$ & $12 / 20 / 2016$ & $\mathrm{n}$ & 24 & jimpy & severe & $\mathrm{N}$ & & 26.9 & & & & 1.2 & & & \\
\hline $\begin{array}{l}\text { CR200319 } \\
\end{array}$ & $11 / 26 / 2016$ & $12 / 19 / 2016$ & $\mathrm{n}$ & 23 & jimpy & severe & $\mathrm{N}$ & & 41.4 & & & & 1.0 & & & \\
\hline CR200320 & $12 / 12 / 2016$ & $1 / 5 / 2017$ & $\mathrm{n}$ & 24 & jimpy & severe & $\mathrm{N}$ & & & & & & & & & \\
\hline CR200321 & $12 / 12 / 2016$ & $12 / 31 / 2016$ & $n$ & 19 & jimpy & severe & $\mathrm{N}$ & & & & & & & & & \\
\hline CR200322 & $12 / 12 / 2016$ & $11 / 16 / 2017$ & $\mathrm{n}$ & 339 & CR-impy & none & $\mathrm{N}$ & & & 102.9 & 88.2 & & & 25.229 & 26.0 & \\
\hline CR200323 & $12 / 12 / 2016$ & $6 / 27 / 2018$ & $\mathrm{y}$ & 562 & CR-impy & none & $\mathrm{N}$ & & & 81.1 & 89.4 & 43.9 & & 15.418 & 17.8 & 19.6 \\
\hline CR200324 & $3 / 30 / 2017$ & $4 / 20 / 2017$ & $\mathrm{n}$ & 21 & jimpy & severe & $\mathrm{N}$ & & & & & & & & & \\
\hline CR200325 & $3 / 30 / 2017$ & $4 / 20 / 2017$ & $\mathrm{n}$ & 21 & jimpy & severe & $\mathrm{N}$ & & & & & & & & & \\
\hline CR200326 & $3 / 30 / 2017$ & $4 / 26 / 2017$ & $\mathrm{n}$ & 27 & jimpy & severe & $\mathrm{N}$ & & & & & & & & & \\
\hline CR200327 & $3 / 30 / 2017$ & $4 / 24 / 2017$ & $n$ & 25 & jimpy & severe & $\mathrm{N}$ & & & & & & & & & \\
\hline $\begin{array}{l}\text { CR200328 } \\
\end{array}$ & $11 / 13 / 2016$ & $10 / 1 / 2017$ & $\mathrm{n}$ & 322 & wild-type & none & $\mathrm{Y}$ & Euthanized inadvertantly & 92.7 & 135.4 & 63.5 & & 31.8 & 18.3 & 8.9 & \\
\hline $\begin{array}{l}\text { CR200329 } \\
\end{array}$ & $11 / 13 / 2016$ & $10 / 1 / 2017$ & $\mathrm{n}$ & 322 & wild-type & none & $\mathrm{Y}$ & Euthanized inadvertantly & 148.7 & 126.7 & 102.4 & & 18.6 & 13.8 & 6.7 & \\
\hline CR200330 & $11 / 13 / 2016$ & $10 / 1 / 2017$ & $\mathrm{n}$ & 322 & wild-type & none & $\mathrm{Y}$ & Euthanized inadvertantly & 85.7 & 109.3 & 120.0 & & 15.3 & 19.4 & 19.1 & \\
\hline CR200081 & $11 / 15 / 2016$ & $6 / 1 / 2017$ & $\frac{n}{n}$ & 198 & wild-type & none & $\mathrm{Y}$ & $\begin{array}{l}\text { Tissue collection } \\
\end{array}$ & 196.0 & 160.7 & 145.0 & & 13.5 & 20.9 & 10.3 & \\
\hline CR200082 & $11 / 15 / 2016$ & $6 / 1 / 2017$ & $\mathrm{n}$ & 198 & CR-impy & none & $\mathrm{Y}$ & Tissue collection & 132.3 & 91.5 & 99.1 & & 13.5 & 15.1 & 20.3 & \\
\hline CR200083 & $11 / 15 / 2016$ & $6 / 2 / 2017$ & $\mathrm{n}$ & 199 & CR-impy & none & $\mathrm{Y}$ & Tissue collection & 120.5 & 93.6 & 96.9 & & 21.5 & 23.7 & 25.2 & \\
\hline CR200084 & $11 / 15 / 2016$ & $6 / 2 / 2017$ & $\mathrm{n}$ & 199 & wild-type & none & $\mathrm{Y}$ & Tissue collection & 170.4 & 137.7 & 78.6 & & 23.7 & 11.5 & 7.3 & \\
\hline CR200061 & $11 / 15 / 2016$ & $5 / 25 / 2017$ & $\mathrm{n}$ & 191 & CR-impy & none & $\mathrm{Y}$ & Tissue collection & 102.5 & 111.7 & 105.4 & & 21.1 & 12.2 & 16.2 & \\
\hline CR200062 & $11 / 15 / 2016$ & $5 / 25 / 2017$ & $\frac{n}{n}$ & 191 & CR-impy & none & $\mathrm{Y}$ & Tissue collection & 56.4 & 122.4 & 63.4 & & 13.3 & 15.1 & 18.3 & \\
\hline CR200063 & $11 / 15 / 2016$ & $5 / 25 / 2017$ & $\mathrm{n}$ & 191 & wild-type & none & $\mathrm{Y}$ & Tissue collection & 109.3 & 115.3 & 57.3 & & 26.3 & 26.3 & 10.8 & \\
\hline CR200064 & $11 / 15 / 2016$ & $5 / 25 / 2017$ & $\mathrm{n}$ & 191 & wild-type & none & $\mathrm{Y}$ & Tissue collection & 88.7 & 101.3 & 82.0 & & 17.4 & 15.6 & $\frac{10.0}{8.0}$ & \\
\hline CR200065 & $11 / 16 / 2016$ & $5 / 30 / 2017$ & $\mathrm{n}$ & 195 & CR-impy & none & $\mathrm{Y}$ & Tissue collection & 42.5 & 100.8 & 131.3 & & 10.0 & 6.4 & 6.7 & \\
\hline CR200075 & $11 / 17 / 2016$ & $5 / 31 / 2017$ & $\mathrm{n}$ & 195 & wild-type & none & $\mathrm{Y}$ & Tissue collection & 82.1 & 32.1 & 23.3 & & 24.0 & 21.3 & 21.1 & \\
\hline CR200076 & $11 / 17 / 2016$ & $5 / 31 / 2017$ & $\mathrm{n}$ & 195 & wild-type & none & $\mathrm{Y}$ & Tissue collection & 162.8 & 70.8 & 98.9 & & 20.5 & 11.6 & 9.4 & \\
\hline CR200077 & $11 / 17 / 2016$ & $5 / 31 / 2017$ & $\mathrm{n}$ & 195 & wild-type & none & $\mathrm{Y}$ & Tissue collection & 120.6 & 95.5 & 108.5 & & 20.5 & 26.0 & 14.1 & \\
\hline CR200078 & $11 / 18 / 2016$ & 6/13/2017 & $\mathrm{n}$ & 207 & CR-impy & none & $\mathrm{Y}$ & Tissue collection & 40.5 & 102.0 & 97.6 & & 19.7 & 13.0 & 7.8 & \\
\hline CR200079 & $11 / 18 / 2016$ & $6 / 13 / 2017$ & $\mathrm{n}$ & 207 & wild-type & none & $\mathrm{Y}$ & Tissue collection & 82.2 & 130.0 & 77.2 & & 12.8 & 15.6 & 3.8 & \\
\hline CR200080 & $11 / 18 / 2016$ & $6 / 12 / 2017$ & $\mathrm{n}$ & 206 & CR-impy & none & $\mathrm{Y}$ & Tissue collection & 87.0 & 78.1 & 63.5 & & 26.3 & 18.6 & 15.8 & \\
\hline CR200085 & $11 / 18 / 2016$ & $6 / 12 / 2017$ & $\mathrm{n}$ & 206 & wild-type & none & $\mathrm{Y}$ & Tissue collection & 75.8 & 113.4 & 104.0 & & 19.7 & 9.3 & 8.3 & \\
\hline CR200071 & $11 / 18 / 2016$ & 6/12/2017 & $\mathrm{n}$ & 206 & CR-impy & none & $\mathrm{Y}$ & Tissue collection & 59.0 & 142.3 & 134.3 & & 8.0 & 16.5 & 8.3 & \\
\hline $\begin{array}{l}\text { CR200086 } \\
\end{array}$ & $11 / 18 / 2016$ & $6 / 13 / 2017$ & $\mathrm{n}$ & 207 & CR-impy & none & $\mathrm{Y}$ & Tissue collection & 79.7 & 112.2 & 100.1 & & 14.3 & 8.512 & 12.0 & \\
\hline CR200098 & $11 / 18 / 2016$ & $6 / 13 / 2017$ & $\mathrm{n}$ & 207 & wild-type & none & $\mathrm{Y}$ & Tissue collection & 90.6 & 130.3 & 115.3 & & 17.9 & 19.54 & 13.0 & \\
\hline $\begin{array}{l}\text { CR200066 } \\
\end{array}$ & $11 / 19 / 2016$ & $5 / 30 / 2017$ & $\mathrm{n}$ & 192 & CR-impy & none & $\mathrm{Y}$ & Tissue collection & 88.4 & 124.4 & 82.9 & & 14.0 & 14.136 & 0.6 & \\
\hline CR200067 & $11 / 19 / 2016$ & $5 / 30 / 2017$ & $\mathrm{n}$ & 192 & CR-impy & none & $\mathrm{Y}$ & Tissue collection & 131.7 & 146.0 & 68.2 & & 11.6 & 13.449 & 9.8 & \\
\hline CR200068 & $11 / 19 / 2016$ & $5 / 30 / 2017$ & $\mathrm{n}$ & 192 & wild-type & none & $\mathrm{Y}$ & Tissue collection & 82.5 & 119.3 & 126.1 & & 14.1 & 20.689 & 14.5 & \\
\hline CR200069 & $11 / 22 / 2016$ & $5 / 30 / 2017$ & $\mathrm{n}$ & 189 & wild-type & none & $\mathrm{Y}$ & Tissue collection & 88.4 & 67.0 & 41.5 & & 19.0 & 9.404 & 8.4 & \\
\hline CR200070 & $11 / 22 / 2016$ & $5 / 30 / 2017$ & $\frac{n}{n}$ & 189 & wild-type & none & $\mathrm{Y}$ & Tissue collection & 88.3 & 80.6 & 77.4 & & 20.1 & 9.051 & 5.2 & \\
\hline CR200072 & $11 / 22 / 2016$ & $6 / 1 / 2017$ & $\mathrm{n}$ & 191 & wild-type & none & $\mathrm{Y}$ & Tissue collection & 110.7 & 170.0 & 124.3 & & 21.7 & 19.759 & 11.8 & \\
\hline CR200073 & $11 / 22 / 2016$ & $6 / 1 / 2017$ & $\mathrm{n}$ & 191 & wild-type & none & $\mathrm{Y}$ & $\begin{array}{l}\text { Tissue collection } \\
\end{array}$ & 145.0 & 152.3 & 116.1 & & 13.5 & 22.028 & 11.4 & \\
\hline CR200331 & $11 / 26 / 2016$ & $5 / 23 / 2017$ & $\mathrm{n}$ & 178 & CR-impy & none & $\mathrm{Y}$ & Euthanized inadvertantly & 110.0 & 196.0 & & & 24.3 & 16.452 & & \\
\hline 074 & $12 / 12 / 2016$ & 2017 & $\mathrm{n}$ & 171 & CR-impy & ne & & Tissue collection & & & & & & 23.557 & & \\
\hline
\end{tabular}

\section{Supplementary Figure 1}



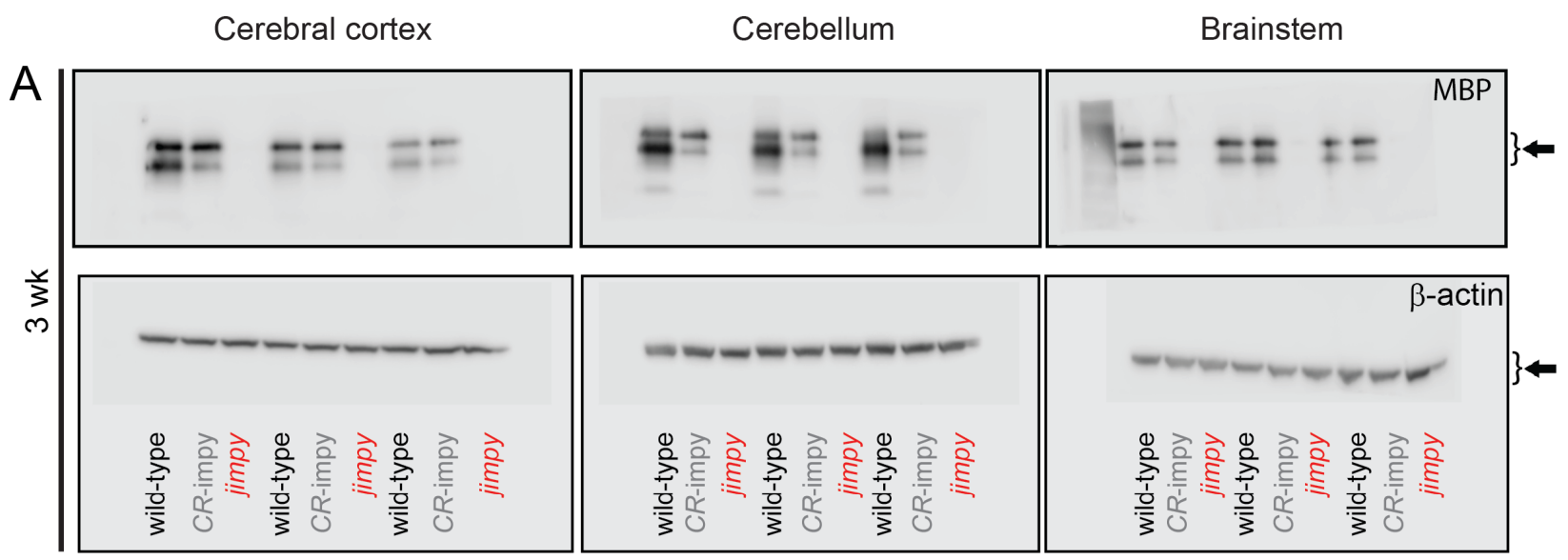

B
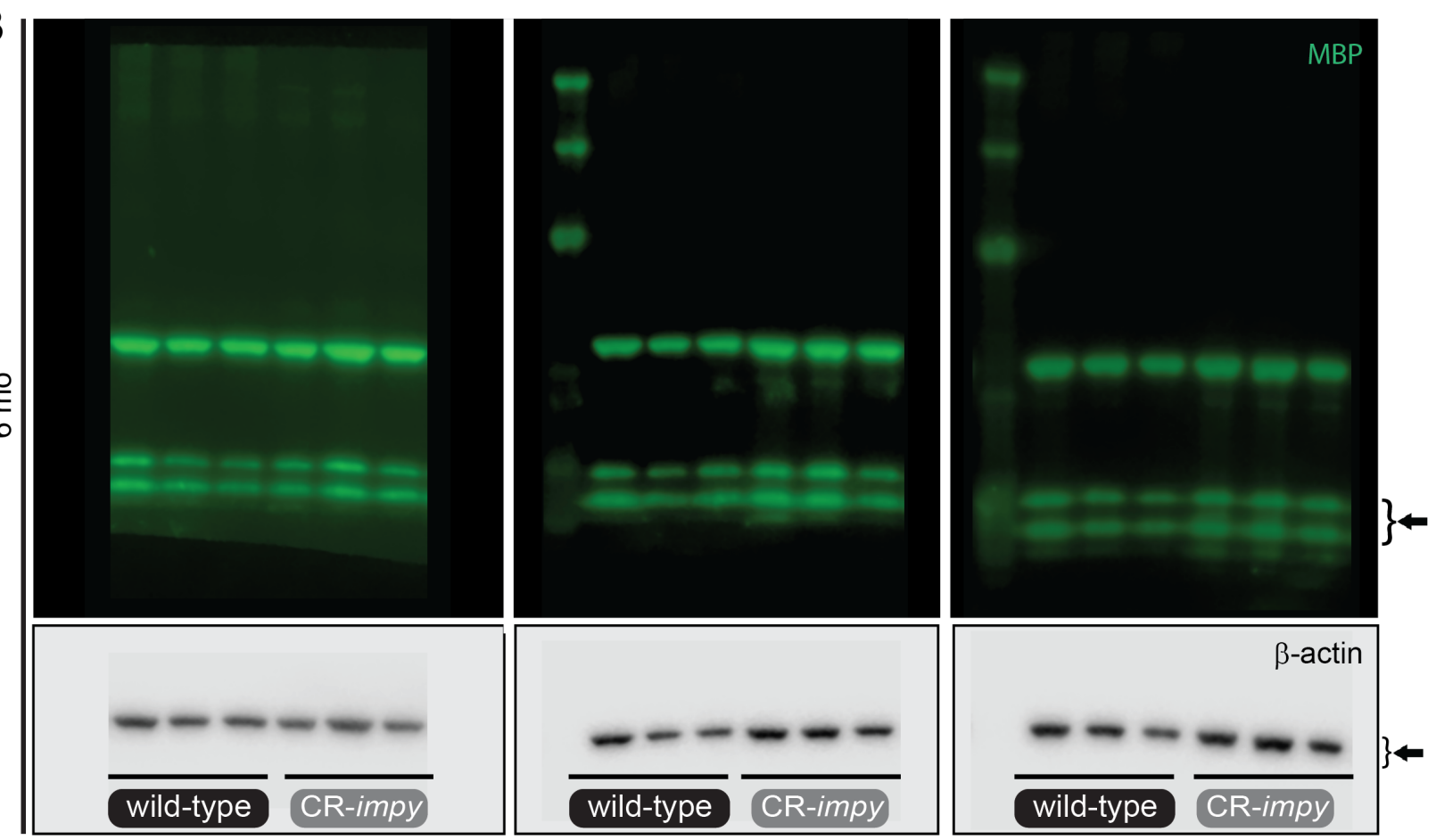

\section{Supplementary Figure 2}

$\mathbf{a}-\mathbf{b}$, Labeled raw images of western blots for all samples in Extended Data Figs. 1d, f. The upper bands in the fluorescent blots in panel B are carry over from chemiluminescent detection of Bactin (bottom panel). 
SUPPLEMENTARY FIGURE 3

1019

\begin{tabular}{|c|c|c|c|c|c|c|c|c|c|c|c|c|c|c|}
\hline \multirow{2}{*}{$\begin{array}{l}\text { Metadata for } 1 \\
\text { Identifier }\end{array}$} & \multirow[t]{2}{*}{ nouse ASO sur } & \multirow[t]{2}{*}{ vival cohort fron } & \multirow{2}{*}{$\begin{array}{l}\text { m Elitt et al. v } \\
\text { Euthanized } \\
\text { at } 8 \text { month } \\
\text { endpoint? }\end{array}$} & \multirow[b]{2}{*}{ Lifespan (days) } & \multirow[b]{2}{*}{ Genotype } & \multirow[b]{2}{*}{ Treatment } & \multirow[b]{2}{*}{ Phenotype } & \multirow[b]{2}{*}{ e Additional phenotype notes } & \multicolumn{3}{|c|}{ mean time to fall (seconds) } & \multicolumn{3}{|c|}{ total distance traveled (meters) } \\
\hline & & & & & & & & & $\begin{array}{c}\text { Rotarod } \\
2 \mathrm{mo}\end{array}$ & $\begin{array}{c}\text { Rotarod } \\
4 \mathrm{mo}\end{array}$ & $\begin{array}{c}\text { Rotarod } \\
6 \mathrm{mo}\end{array}$ & $\begin{array}{l}\text { Open field } \\
2 \text { mo }\end{array}$ & $\begin{array}{c}\text { Open field } \\
4 \text { mo }\end{array}$ & $\begin{array}{l}\text { Open field } \\
6 \mathrm{mo}\end{array}$ \\
\hline ASO00091 & $11 / 23 / 2017$ & $7 / 20 / 2018$ & $\mathrm{y}$ & 239 & jimpy & ASO Plp1.a & mild & $\begin{array}{c}\text { Periorbital area inflammation, } \\
\text { left eve }\end{array}$ & 32.9 & 22.4 & 5.6 & 22.0 & 18.0 & 18.0 \\
\hline ASO00095 & $11 / 23 / 2017$ & $7 / 20 / 2018$ & $\mathrm{y}$ & 239 & jimpy & ASO Plpl.a & mild & $\begin{array}{c}\text { Periorbital area inflammation, } \\
\text { bilateral }\end{array}$ & 22.3 & 24.6 & unable to train & 19.6 & 13.7 & 14.0 \\
\hline ASO000S1 & $12 / 7 / 2017$ & $12 / 28 / 2017$ & $\mathrm{n}$ & 21 & iimpv & uniniected & severe & & & & & & & \\
\hline ASO000S2 & $12 / 7 / 2017$ & $12 / 28 / 2017$ & $\mathrm{n}$ & 21 & iimpy & ASO control & severe & & & & & & & \\
\hline ASO000S3 & $12 / 7 / 2017$ & $12 / 29 / 2017$ & $\mathrm{n}$ & 22 & iimpv & ASO control & severe & & & & & & & \\
\hline ASO000S4 & $12 / 7 / 2017$ & $12 / 27 / 2017$ & $\mathrm{n}$ & 20 & izimpv & ASO control & severe & & & & & & & \\
\hline ASO000S5 & $12 / 8 / 2017$ & $12 / 24 / 2017$ & $\mathrm{n}$ & 16 & iimpy & uminjected & severe & & & & & & & \\
\hline ASO000S6 & $12 / 8 / 2017$ & $12 / 27 / 2017$ & $\mathrm{n}$ & 19 & iimpv & uniniected & severe & & & & & & & \\
\hline ASO000S7 & $12 / 11 / 2017$ & $12 / 26 / 2017$ & $\mathrm{n}$ & 15 & iimpy & uniniected & severe & & & & & & & \\
\hline ASO000S8 & $12 / 5 / 2017$ & $12 / 25 / 2017$ & $\mathrm{n}$ & 20 & iimpy & uminjected & severe & & & & & & & \\
\hline ASO000S9 & $12 / 5 / 2017$ & $12 / 25 / 2017$ & $\mathrm{n}$ & 20 & iimpv & uniniected & severe & & & & & & & \\
\hline ASO000S10 & $12 / 8 / 2017$ & $12 / 28 / 2017$ & $\mathrm{n}$ & 20 & jimpy & uninjected & severe & $\begin{array}{l}\text { Found with hind-limb } \\
\text { paralysis, required } \\
\text { euthanization }\end{array}$ & & & & & & \\
\hline ASO000S11 & $12 / 8 / 2017$ & $12 / 30 / 2017$ & $\mathrm{n}$ & 22 & iimpy & uniniected & severe & & & & & & & \\
\hline ASO000S12 & $12 / 8 / 2017$ & $12 / 28 / 2017$ & $\mathrm{n}$ & 20 & jimpy & uninjected & severe & $\begin{array}{c}\text { Found with hind-limb } \\
\text { paralysis, required } \\
\text { euthanization }\end{array}$ & & & & & & \\
\hline AS000103 & $12 / 27 / 2017$ & $8 / 27 / 2018$ & $\mathrm{y}$ & 243 & jimpy & ASO Plp1.b & mild & $\begin{array}{c}\text { Periorbital area inflammation, } \\
\text { right eve }\end{array}$ & unable to train & unable to train & unable to train & 13.2 & 6.2 & 4.3 \\
\hline AS000104 & $12 / 27 / 2017$ & $8 / 27 / 2018$ & $\mathrm{v}$ & 243 & iimpv & ASO Plp1.b & mild & & 39.4 & 49.5 & 27.8 & 14.5 & 9.0 & 11.3 \\
\hline ASO000S13 & $12 / 27 / 2017$ & $1 / 18 / 2018$ & $\mathrm{n}$ & 22 & iimpy & uniniected & severe & & & & & & & \\
\hline AS000105b & $12 / 28 / 2017$ & $8 / 27 / 2018$ & $\mathrm{v}$ & 242 & iimpv & ASO Plp1.b & mild & & 51.5 & 37.2 & 36.9 & 13.8 & 12.7 & 8.8 \\
\hline AS000106 & $12 / 28 / 2017$ & $8 / 27 / 2018$ & $\mathrm{v}$ & 242 & iimpv & ASO Plp1.b & mild & & 34.7 & 27.4 & 37.2 & 15.0 & 15.5 & 8.9 \\
\hline $\begin{array}{l}\mathrm{A} \text { ASO00107 } \\
\end{array}$ & $12 / 30 / 2017$ & $8 / 27 / 2018$ & $\mathrm{v}$ & 240 & immpry & ASO Pln1 a & mild & & Inahle to train & unable to train & Inahle to train & 113 & 157 & 128 \\
\hline AS000108 & $12 / 30 / 2017$ & $8 / 27 / 2018$ & $\mathrm{y}$ & 240 & jimpy & ASO Plp1.a & mild & $\begin{array}{c}\text { Periorbital area inflammation, } \\
\text { bilateral }\end{array}$ & unable to train & 17.0 & unable to train & 10.1 & 15.1 & 18.5 \\
\hline $\begin{array}{l}\text { ASO00109 } \\
\end{array}$ & $12 / 31 / 2017$ & $8 / 27 / 2018$ & $\mathrm{y}$ & 239 & iimpy & ASO Plp1.a & mild & & 14.3 & 34.1 & 3.3 & 15.1 & 14.2 & 10.7 \\
\hline ASO000S14 & $12 / 18 / 2017$ & $1 / 5 / 2018$ & $\mathrm{n}$ & 18 & iimpv & uninjected & severe & & & & & & & \\
\hline ASO000S15 & $12 / 18 / 2017$ & $1 / 5 / 2018$ & $\mathrm{n}$ & 18 & iimpy & uniniected & severe & & & & & & & \\
\hline $\begin{array}{l}\text { ASO0000S16 } \\
\end{array}$ & $12 / 18 / 2017$ & $1 / 4 / 2018$ & $\mathrm{n}$ & 17 & impy & uniniected & severe & & & & & & & \\
\hline $\begin{array}{l}\text { ASO0000S17 } \\
\end{array}$ & $1 / 6 / 2018$ & $1 / 25 / 2018$ & $\mathrm{n}$ & 19 & iimpv & ASO control & severe & & & & & & & \\
\hline ASO000S18 & $1 / 6 / 2018$ & $1 / 25 / 2018$ & $\mathrm{n}$ & 19 & iimpy & ASO control & severe & & & & & & & \\
\hline ASO000S19 & $12 / 29 / 2017$ & $1 / 18 / 2018$ & $\mathrm{n}$ & 20 & impy & uninjected & severe & & & & & & & \\
\hline AS000115 & $1 / 22 / 2018$ & 9/7/2018 & $\mathrm{v}$ & 228 & iimpv & ASO Plp1.b & mild & & 41.9 & 19.2 & 8.1 & 11.9 & 8.4 & 3.3 \\
\hline ASO000S 20 & $1 / 22 / 2018$ & $3 / 30 / 2018$ & $\mathrm{n}$ & 67 & iimpy & ASO Plp1.b & mild & & 31.1 & dead & dead & 20.5 & dead & dead \\
\hline $\begin{array}{l}\text { ASO000117 } \\
\end{array}$ & $1 / 22 / 2018$ & 9/7/2018 & $\mathrm{y}$ & 228 & impy & ASO Plp1.b & mild & & 40.1 & unable to train & unable to train & 14.8 & 16.4 & 18.6 \\
\hline AS000110 & $1 / 18 / 2018$ & 9/17/2018 & $\mathrm{y}$ & 242 & iimpv & ASO Plpl.b & mild & Upper back inflammation & unable to train & unable to train & unable to train & 23.9 & 25.2 & 17.3 \\
\hline ASO00096 & $12 / 7 / 2017$ & $7 / 23 / 2018$ & $\mathrm{y}$ & 228 & wild-type & ASO control & none & & & & & & & \\
\hline ASO00097 & $12 / 7 / 2017$ & $7 / 23 / 2018$ & $\mathrm{y}$ & 228 & wild-type & ASO control & none & & & & & & & \\
\hline ASO00099 & $12 / 7 / 2017$ & $7 / 23 / 2018$ & $\mathrm{y}$ & 228 & wild-rype & ASO control & none & & & & & & & \\
\hline $\begin{array}{l}\text { AS } 000100 \\
\end{array}$ & $12 / 5 / 2017$ & $7 / 23 / 2018$ & $\mathrm{y}$ & 230 & wild-type & uninjected & none & & 111.1 & 110.8 & 63.7 & 8.2 & 1.4 & 3.9 \\
\hline AS000101 & $12 / 5 / 2017$ & $7 / 23 / 2018$ & $\mathrm{y}$ & 230 & wild-type & uninjected & none & & 76.8 & 94.9 & 64.6 & 12.0 & 3.3 & 2.9 \\
\hline AS000102 & $12 / 5 / 2017$ & $7 / 23 / 2018$ & $\mathrm{y}$ & 230 & wild-type & uninjected & none & & 53.1 & 54.3 & 67.0 & 8.0 & 7.9 & 3.8 \\
\hline AS000111 & $1 / 19 / 2018$ & $9 / 17 / 2018$ & $\mathrm{y}$ & 241 & wild-type & uniniected & none & & 84.0 & 80.5 & 67.4 & 37.2 & 32.9 & 21.7 \\
\hline AS000112 & $1 / 19 / 2018$ & $9 / 17 / 2018$ & $\mathrm{y}$ & 241 & wild-type & uninjected & none & & 107.0 & 61.0 & 76.3 & 17.9 & 7.5 & 6.2 \\
\hline AS000122 & $4 / 5 / 2018$ & $12 / 14 / 2018$ & $\mathrm{y}$ & 253 & wild-type & ASO control & none & & & & 3.7 & & & 14.3 \\
\hline AS000123 & $4 / 5 / 2018$ & $12 / 14 / 2018$ & $\mathrm{y}$ & 253 & wild-type & ASO control & none & & & & 18.3 & & & 1.8 \\
\hline AS000124 & $4 / 5 / 2018$ & $12 / 14 / 2018$ & $\mathrm{y}$ & 253 & wild-type & ASO control & none & & & & 89.4 & & & 20.5 \\
\hline AS000125 & $4 / 5 / 2018$ & $12 / 14 / 2018$ & $\mathrm{y}$ & 253 & wild-type & ASO control & none & & & & 107.1 & & & 13.2 \\
\hline AS000126 & $4 / 13 / 2018$ & $12 / 13 / 2018$ & $\mathrm{y}$ & 244 & wild-type & ASO control & none & & & & 123.7 & & & 13.0 \\
\hline AS000127 & $4 / 13 / 2018$ & $12 / 13 / 2018$ & $\mathrm{y}$ & 244 & wild-type & ASO control & none & & & & 45.4 & & & 20.4 \\
\hline AS000128 & $4 / 14 / 2018$ & \multirow{3}{*}{\multicolumn{3}{|c|}{ ongoing (still alive) }} & wild-type & ASO control & none & & & & & & & \\
\hline ASO000S21 & $5 / 4 / 2018$ & & & & wild-type & ASO control & none & & & & & & & \\
\hline ASO0000S22 & $5 / 4 / 2018$ & & & & $\begin{array}{l}\text { wild-type } \\
\text {. }\end{array}$ & ASO control & none & & & & & & & \\
\hline
\end{tabular}

\section{Supplementary Figure 3}

Table of metadata for all mice in Kaplan-Meier survival plot in Fig. 4c (as of 12-25-18 with two 
bioRxiv preprint doi: https://doi.org/10.1101/508192; this version posted December 31, 2018. The copyright holder for this preprint (which was not certified by peer review) is the author/funder, who has granted bioRxiv a license to display the preprint in perpetuity. It is made available under aCC-BY-NC-ND 4.0 International license.

A

Cerebral cortex
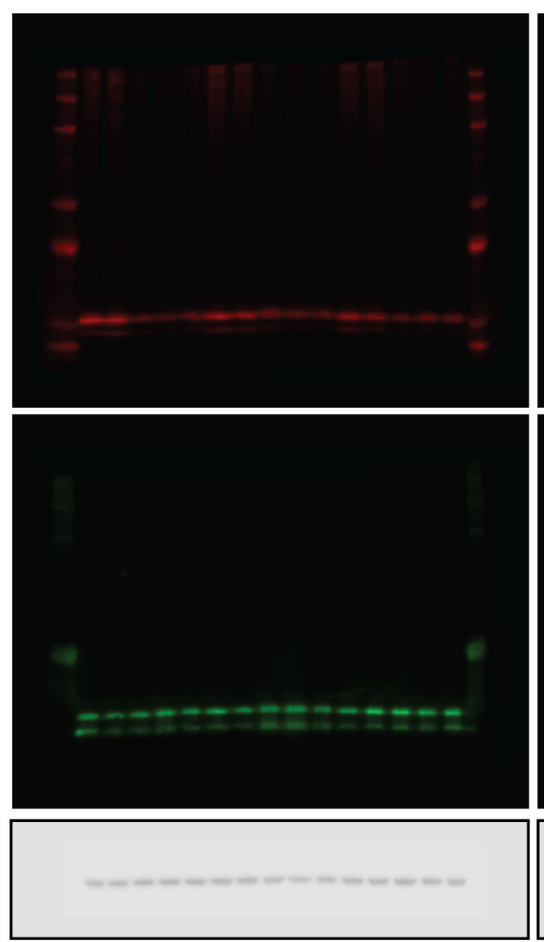

B
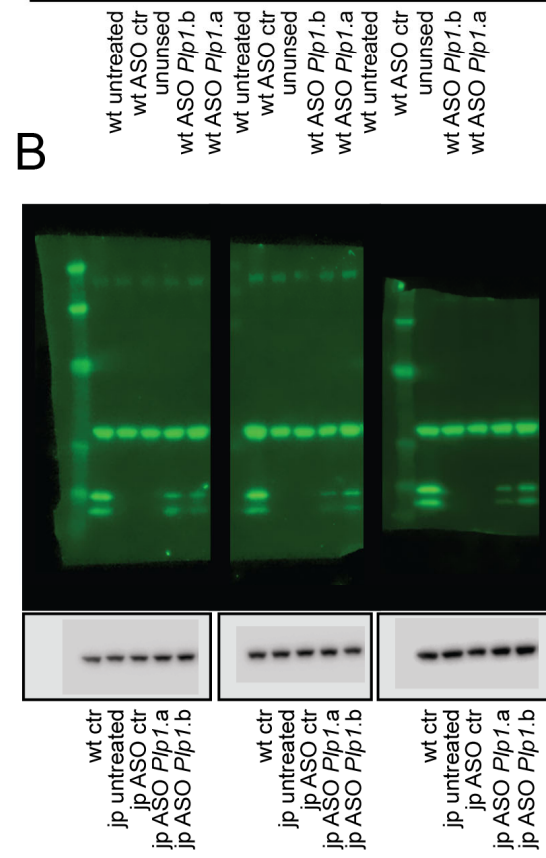

Cerebellum
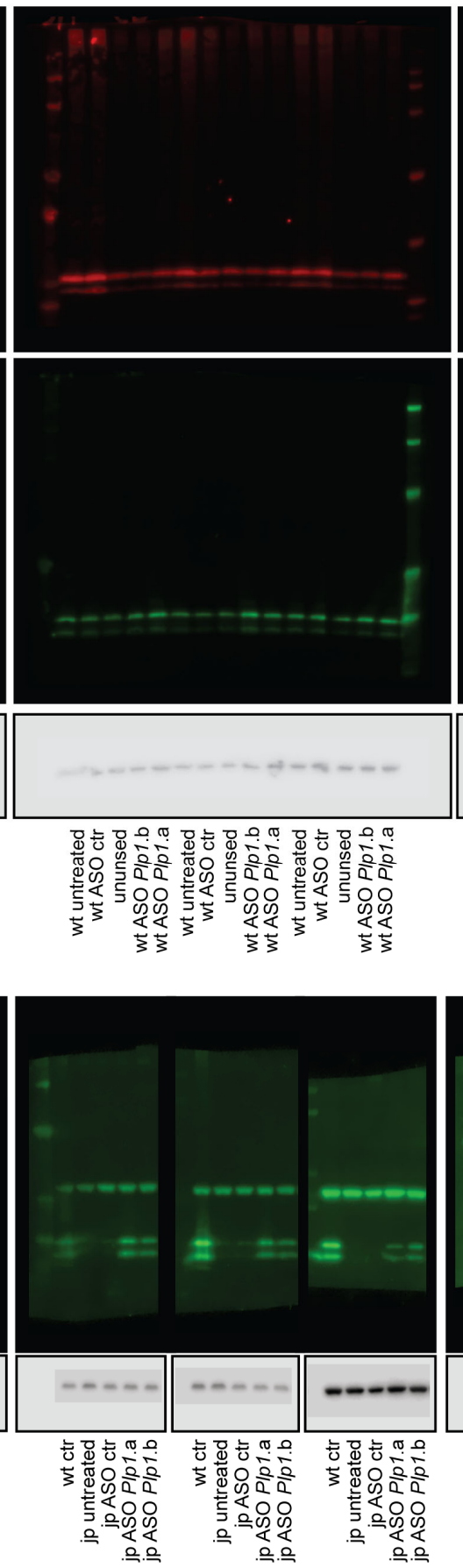

Brainstem
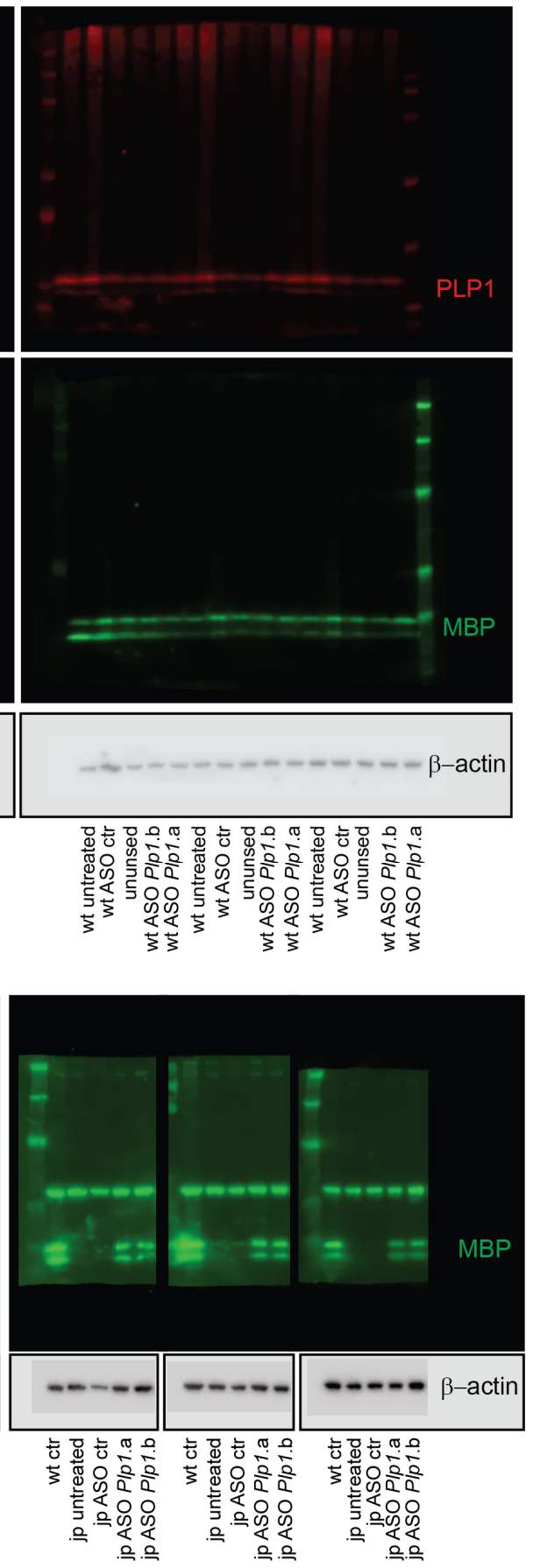

\section{Supplementary Figure 4}

a-b, Labeled raw images of western blots for all samples in Extended Data Figs. 7b, c, e. The upper bands in the fluorescent blots in panel B are carry over from chemiluminescent detection of Bactin (bottom panel). 
SUPPLEMENTARY VIDEOS 1-4 (four separate MP4 files)

Supplementary Video 1 | CRISPR-mediated knockdown of Plp1 in jimpy mice rescues neurological phenotypes at 3 weeks of age.

Video comparison of wild-type, jimpy, and CR-impy mice at 3 weeks of age.

Supplementary Video 2 | CRISPR-mediated knockdown of Plp1 in jimpy mice shows sustained rescue of neurological phenotypes at 18 months of age.

Video comparison of wild-type and CR-impy mice at 18 weeks of age (study endpoint).

Supplementary Video 3 | Postnatal delivery of Plp1-targeted ASOs to jimpy mice rescues neurological phenotypes at 3 weeks of age.

Video comparison of wild-type and jimpy mice treated with control and Plpl-targeting ASOs at 3 weeks of age.

Supplementary Video 4 | Postnatal delivery of Plp1-targeted ASOs to jimpy mice shows sustained rescue of neurological phenotypes at 6 months of age.

Video comparison of wild-type and jimpy mice treated with control and Plpl-targeting ASOs at 6 months of age. 


\section{Supplementary References}

1. J. Y. Garbern et al., Proteolipid protein is necessary in peripheral as well as central myelin. Neuron 19, 205-218 (1997).

2. J. Y. Garbern et al., Patients lacking the major CNS myelin protein, proteolipid protein 1, develop length-dependent axonal degeneration in the absence of demyelination and inflammation. Brain 125, 551-561 (2002).

3. P. Lassuthova et al., Three new PLP1 splicing mutations demonstrate pathogenic and phenotypic diversity of Pelizaeus-Merzbacher disease. Journal of child neurology 29, 924931 (2014).

4. E. A. Sistermans et al., A (G-to-A) mutation in the initiation codon of the proteolipid protein gene causing a relatively mild form of Pelizaeus-Merzbacher disease in a Dutch family. Hum Genet 97, 337-339 (1996).

5. C. K. Hand, G. Bernard, M.-P. Dubé, M. I. Shevell, G. A. Rouleau, A Novel PLP1 Mutation Further Expands the Clinical Heterogeneity at the Locus. The Canadian Journal of Neurological Sciences 39, 220-224 (2014). 